NBER WORKING PAPER SERIES

\title{
BOND FINANCE, BANK CREDIT, AND AGGREGATE FLUCTUATIONS IN AN OPEN ECONOMY
}

\author{
Roberto Chang \\ Andrés Fernández \\ Adam Gulan \\ Working Paper 22377 \\ http://www.nber.org/papers/w22377 \\ NATIONAL BUREAU OF ECONOMIC RESEARCH \\ 1050 Massachusetts Avenue \\ Cambridge, MA 02138 \\ June 2016
}

Prepared for the Spring 2016 Carnegie Rochester NYU Conference on Public Policy. We thank Mark Aguiar, Andrea Ferrero, Leonor Modesto, Maria Pía Olivero and Damiano Sandri for useful discussions. We have also benefited from conversations with Julian Caballero, Luis Catão, Fiorella De Fiore, Pablo D'Erasmo, Markus Haavio, Bengt Holmström, Esa Jokivuolle, Joachim Jungherr, Enrique Mendoza, Guillermo Ordoñez, Vincenzo Quadrini, Antti Ripatti, Ctirad Slavík, Christian Upper, Jaume Ventura, Mirko Wiederholt, and participants of several seminars and conferences. The opinions in this paper are solely those of the authors and do not necessarily reflect the opinion of the Inter-American Development Bank or its board of directors, nor the countries that they represent, nor of the Bank of Finland, nor of the European System of Central Banks. Chang acknowledges the hospitality of CREI. Santiago Téllez provided excellent research assistance. Further comments will be most appreciated. The views expressed herein are those of the authors and do not necessarily reflect the views of the National Bureau of Economic Research.

NBER working papers are circulated for discussion and comment purposes. They have not been peer-reviewed or been subject to the review by the NBER Board of Directors that accompanies official NBER publications.

(C) 2016 by Roberto Chang, Andrés Fernández, and Adam Gulan. All rights reserved. Short sections of text, not to exceed two paragraphs, may be quoted without explicit permission provided that full credit, including $\odot$ notice, is given to the source. 
Bond Finance, Bank Credit, and Aggregate Fluctuations in an Open Economy

Roberto Chang, Andrés Fernández, and Adam Gulan

NBER Working Paper No. 22377

June 2016

JEL No. F3,F4

\begin{abstract}
$\underline{\text { ABSTRACT }}$
Corporate sectors in emerging markets have noticeably increased their reliance on foreign financing, presumably reflecting low global interest rates. The evidence also shows a rebalancing from bank loans towards bonds. To study these developments, we develop a dynamic open economy model where these modes of finance are determined endogenously. The model replicates the stylized facts following a drop in world interest rates; in particular, rebalancing towards bonds occurs because bank credit becomes relatively more expensive, reflecting the scarcity of bank equity. More generally, the model is suitable for studying interactions between modes of finance and the macroeconomy.
\end{abstract}

Roberto Chang

Rutgers University

Department of Economics

75 Hamilton Street

New Brunswick, NJ 08901

and NBER

chang@econ.rutgers.edu

Andrés Fernández

Research Department

Inter-American Development Bank

1300 New York Avenue NW

Washington DC 20577

andresf@iadb.org
Adam Gulan

Monetary Policy and Research Department

Bank of Finland

Snellmaninaukio

Helsinki, FI00101

Finland

adam.gulan@bof.fi 


\section{Introduction}

In recent years, the corporate sector in emerging market economies has increased its reliance on foreign financing considerably. This trend became more marked during the period of low global interest rates following the global financial crisis, and has generated a lively debate regarding its interpretation and policy implications. An optimistic view is that the increase in corporate liabilities is a natural response to favorable interest rates and relatively favorable investment prospects in emerging countries. A less sanguine view is that larger foreign liabilities are dangerous and place emerging economies in a precarious position.

Understanding this phenomenon has been complicated by the observation that it has largely reflected increased bond issuance by emerging economies' firms, in contrast to the bank loans which dominated capital flows in the past.1 To illustrate, Figure $12^{2}$ reproduces a chart from Powell (2014), describing the evolution of foreign corporate liabilities in Brazil, Chile, Colombia, Mexico and Peru, as well as an average (LAC-5). The figure shows a clear acceleration in the amount of both bonds and loans owed by Latin American firms. It also shows that the relative importance of bonds has increased since the start of the century and, more emphatically, since the global crisis. For an average country in the figure, the share of bonds in the stock of international corporate debt increased from $22 \%$ in 2000 to $43 \%$ in 2013 . This process has taken place while, simultaneously, debt-to-output ratios have increased in emerging economies. In 2005 debt-to-quarterly GDP for LAC-5 was about 30\%, while by the end of 2013 it had almost doubled, just below $60 \% 3^{3}$

Figure 2 shows that the surge of external borrowing has been accompanied by a drop in the interest rates faced by emerging economies. This drop was partly related to the low global

\footnotetext{
${ }^{1}$ Note also that these developments have been dominated by corporate debt rather than sovereign debt, which was prevalent in earlier periods. As shown in Caballero, Fernández and Park (2016), corporate bond issuance has also increased domestically, but not as much as the one issued in international markets. Sovereigns, on the other hand, have displayed a tendency of substituting international bond issuance with domestic bond issuance.

${ }^{2}$ Figures and tables are gathered at the end of the paper.

${ }^{3}$ We measure debt on a residence basis. Stylized facts hold as well when debt is measured on a nationality basis. The Online Appendix reproduces Figure 1 by scaling the amount of debt by GDP.
} 
interest rates since the onset of the crisis, here measured by real U.S. bond rates. However, since the early 2000s it was also accompanied by the low spreads that these countries are charged on top of the riskless rate. $4^{4}$ Low spreads continued despite the short-lasting jump following the panic of 2008 .

This paper sheds light on the interpretation and implications of these events by developing a stochastic dynamic equilibrium model of an open economy in which the quantities of direct versus intermediated finance are determined endogenously. Our calibrated model embeds the static, partial equilibrium model of Holmström and Tirole (1997, henceforth HT) into an otherwise standard dynamic setting. As in HT, the production of capital goods requires finance from outside investors. As we are interested in foreign borrowing by the emerging economies, we assume in the model that this outside lending comes from abroad. Due to moral hazard problems, only a fraction of this production can be financed directly from the outsiders, while another portion can be financed only with the participation of monitors or "banks" 5 In each period, therefore, the amounts of bank loans and direct finance are endogenous and depend on variables such as the price of capital goods and the equity of capital producing firms and banks. The latter are determined in a dynamic general equilibrium, in contrast to HT. Hence our model allows for a study of the interaction between modes of finance and the macroeconomy, and is of independent interest.

As a main finding, the model yields an intuitive economic explanation of the joint dynamics of bonds, bank loans, and interest rates summarized by Figures 1 and 2. In the model, an exogenous drop in world interest rates leads to an increase in the demand for capital goods and a corresponding increase in their relative price. The latter raises the profitability of capital goods production; given existing corporate equity, this raises pledgeable income and

\footnotetext{
${ }^{4}$ These favorable borrowing conditions have been enjoyed not only by sovereign borrowers, as depicted by the EMBIG spread in Figure 2 but also by non-financial corporations, as measured by the CEMBI which has also followed the dynamics of EMBIG.

${ }^{5}$ We abstract from equity issuance as a source of funding. In practice this is not far from reality, particularly for emerging market economies. Gozzi, Levine and Schmukler (2010) examine firm-level patterns in international financing decisions over the period 1991-2005 finding that debt issues in public markets are much more important as a source of finance for firms than equity issues, with debt accounting for $80 \%$ of the total funds raised through public markets.
} 
allows for increases in both corporate bonds and bank loans. At the same time, however, the return to the equity of the banking sector goes up, reflecting that such equity is scarce and slow to adjust. Hence bank finance becomes relatively more costly than direct finance and, accordingly, the ratio of corporate bonds to bank loans goes up. These implications are all in line with the empirical observations mentioned above, and reflect the crucial roles of corporate equity and bank equity in the adjustment process.

The model is suitable to tackle several related questions. In particular, it has been conjectured that the observed increase in direct finance relative to indirect finance in emerging countries may reflect changes in the underlying technology of finance (e.g. costs of monitoring or degree of moral hazard) which, at the same time, may have made those countries more vulnerable to external shocks. Our model provides a less pessimistic perspective: as we show, permanent changes in moral hazard parameters or monitoring costs can indeed result in an increase in the ratio of commercial bonds to loans, but also imply smoother responses to interest rate shocks. This is intuitive, reflecting that the mode of finance provides an additional margin of adjustment in an environment of low interest rates. 6

Finally, we extend the model to allow for an exports commodity sector, and analyze the impact of shocks to world commodity prices. This is of interest because many emerging economies, including the ones featured in Figures 1 and 2, rely heavily on commodity exports whose prices have experienced large fluctuations since the millennium and considerable increases during the period of low global interest rates. In the extended model, a favorable shock to the prices of export commodities causes an increase in the demand for capital goods, raising their price. This, in turn, leads to increased production of capital goods, larger quantities of both direct and indirect finance, and an increase in the bonds to loans ratio, just as in the baseline model and because of the same reasons. The extended model thus confirms the insights of the baseline model as to the mechanism by which ex-

\footnotetext{
${ }^{6}$ In contrast, Shin (2013) and others have argued that larger foreign liabilities are dangerous and place emerging economies in a precarious position. Shin (2013) has emphasized that the increase in commercial debt can be problematic because of the possibility of exacerbating currency mismatch problems, which we do not address in this paper.
} 
ternal shocks may explain the dynamics of bonds and loans. It also rationalizes the idea that favorable commodity prices may have acted in conjunction with lower interest rates in generating such dynamics.

Our work is related to several strands of literature. One is a set of empirical studies that have documented recent international trends in corporate debt issuance and analyzed the determinants of corporate debt choice. Shin (2013) and Turner (2014) report the considerable increase in foreign currency borrowing in international bond markets by emerging market corporations. $]^{7}$ Powell (2014) and Bastos, Kamil and Sutton (2015) carefully document this phenomenon for Latin American economies while Caballero, Fernández and Park (2016) provide similar evidence for Asia and Eastern Europe..$^{8}$ Our model can be seen as a theoretical explanation of the above empirical evidence. In particular, it is consistent with the findings of Caballero, Fernández and Park (2016), that aggregate investment has responded to low credit spreads during the period of corporate debt expansion in emerging economies. 9

In developing our model, we build upon HT and other basic contributions that have provided microfoundations for the choice between bank and market finance under moral hazard. ${ }^{10}$ Our work extends this line of research by endogenizing the choice between bank

\footnotetext{
${ }^{7}$ Bruno and Shin (2015) document the distribution of corporate bond issuance in emerging economies across sectors. The oil and gas sector accounts for over $23 \%$ of total issuance, while the telecoms and utilities sectors also represent a large portion of the issuance activity (24\%). They argue that, to the extent that the cash flows of the latter sectors are mainly in domestic currency, the issuance of US dollar bonds entails some currency exposure for the issuing firms. Also, part of the borrowing has been done by firms' offshore affiliates and therefore does not show up in residence-based statistics.

${ }^{8}$ In terms of the maturity of the corporate bonds in emerging economies, Caballero, Fernández and Park (2016) document a median maturity at issuance of about 7 years between 2000 and 2014. Bruno and Shin (2015), in turn, report an increase in the maturity for the bond issuance since 2001.

${ }^{9}$ On the other hand, using firm-level data, Bruno and Shin (2015) find that emerging market corporates tend to borrow more in US dollars when they already hold large cash balances. This indicates that cash needs for investment may not be the only motivation for bond issuance; instead, Bruno and Shin suggest, firms have been engaging in carry trades. The question of whether corporates borrow for investment purposes or carry trades remains open. Using firm level data, Alfaro et al. (2016) find that the evidence is mixed: they document an increase in tangible fixed asset investment among firms in emerging markets that exceeds the average for the full emerging market sample in the pre-Asian crisis period; but they also uncover some cases of weaker liquidity, solvency, and corporate distress indications compared to the pre-Asian crisis average. See also Caballero, Panizza and Powell (2016) find that non-financial firms in emerging economies are more likely to act like financial intermediaries in countries with tighter capital controls.

${ }^{10}$ Repullo and Suarez (2000) also endogenize the choice between bank finance and market finance within an environment where firms are heterogeneous in the amount of available net worth. See also Diamond (1991), Rajan (1992), Besanko and Kanatas (1993) and Bolton and Scharfstein (1996).
} 
finance and market finance embedding HT's dual moral hazard problem within a dynamic, general equilibrium context of a small open economy.

Our approach emphasizes the role of corporate equity and bank equity as determinants of the demand for credit, like HT. We go beyond HT, however, in exploring dynamics as well as macroeconomic implications. Chen (2001), Aikman and Paustian (2006), and Meh and Moran (2010) have also embedded HT into dynamic equilibrium settings. A crucial difference with our paper, however, is that none of these forerunners modeled the endogenous determination of direct finance versus intermediated finance, which is the central concern of our paper.

Perhaps the closest antecedent of our study is the recent paper by De Fiore and Uhlig (2015) ${ }^{11}$. They develop a model in which firms choose to finance productive projects either directly or with the help of financial intermediaries; the latter can draw a signal about the probability of project success, which helps avoiding bankruptcy. De Fiore and Uhlig (2015) then argue that their model can account for a simultaneous fall in bank loans and an increase in bond issuance by US firms during the Great Recession; this is the case if firmlevel uncertainty and intermediation costs of banks happen to increase at the same time. Our paper coincides with De Fiore and Uhlig's in modeling the endogenous determination of direct finance versus bank finance in dynamic macro models, but it is very different otherwise. We start from different facts: in emerging economies, the amounts of bonds and bank loans have moved in the same direction; in contrast, De Fiore and Uhlig's objective was to explain the observed fall in loans and increase in bonds in the US. More notably, our theoretical framework is quite different from theirs: ours emphasizes the key role of corporate and bank equity, which allows us to provide an economic explanation of the links between observable changes in world interest rates and commodity prices and the dynamic behavior of bonds and loans. Finally, De Fiore and Uhlig's model is a closed economy one, while we model an

\footnotetext{
${ }^{11}$ De Fiore and Uhlig (2011) first develops the model in De Fiore and Uhlig (2015), providing steady state analysis and focusing on long run differences between the US and the Euro area.
} 
open economy in order to understand the international phenomena described above 12

The plan of the paper is as follows. Section 2 presents the basic model, outlines its solution, and discusses its theoretical implications. Section 3 describes a baseline calibration. Section 4 examines dynamic implications of the calibrated model. Section 5 extends the model to allow for a commodity exports sector and discusses the implications. Final remarks are given in Section 6 .

\section{The Model}

Our focus is on a small open economy. Time is discrete and indexed by $t=0,1, \ldots$. The economy is inhabited by households, final goods producers and holding companies which produce new capital goods. The rest of the world acts as a supplier for credit, both for the holding companies as well as for the households.

\subsection{Households and Final Goods Production}

Our specification of the household sector and of the production of final goods is standard, so it will be brief. This is because, for our purposes, the main aspect of this part of the model is to generate a dynamic demand for capital goods. Accordingly, we assume that producing final goods requires capital, which is owned by domestic households, and that the relative price of capital is time varying.

There is a freely traded final good that will serve as numeraire. Competitive domestic firms produce final goods with capital and labor via a Cobb-Douglas function:

$$
Y_{t}=\mathcal{A}_{t} K_{t}^{\alpha} H_{t}^{1-\alpha}
$$

with $Y_{t}$ denoting output of final goods, $K_{t}$ capital input, $H_{t}$ labor input, $\mathcal{A}_{t}$ total factor

\footnotetext{
${ }^{12}$ See also Crouzet (2015), which develops a dynamic model where banks offer more flexibility than market lenders if a firm is in financial distress; banks lending is more restrictive than market lending otherwise. The role of bank equity, which is critical in our framework, is also absent in Crouzet's setup.
} 
productivity (assumed to be exogenous) and $0<\alpha<1$.

Competitive factor markets yield the usual marginal conditions

$$
\begin{aligned}
\alpha Y_{t} & =r_{t}^{K} K_{t} \\
(1-\alpha) Y_{t} & =w_{t} H_{t}
\end{aligned}
$$

where $r_{t}^{K}$ and $w_{t}$ denote the rental rate of capital and the wage rate, respectively.

Households are the owners of productive factors, including capital. They can also borrow or lend in world markets at a gross interest rate $\Psi_{t+1} R_{t+1}^{*}$, where $R_{t+1}^{*}$ is the safe world interest rate between periods and $\Psi_{t+1}$ is a country specific spread.

The household's budget constraint in period $t$ is, then,

$$
C_{t}+Q_{t} X_{t}+\Psi_{t} R_{t}^{*} D_{t}=w_{t} H_{t}+r_{t}^{K} K_{t}+D_{t+1}+\left(1-\phi^{f}\right) \Pi_{t}
$$

where $C_{t}$ denotes consumption of the final good, $X_{t}$ purchases of new capital, $Q_{t}$ the price of new capital, and $D_{t+1}$ the amount borrowed abroad. Finally, $\left(1-\phi^{f}\right) \Pi_{t}$ denotes dividends from capital producing firms, which are transferred to the household, as described below.

The spread $\Psi_{t}$ is exogenous to the household but, as discussed by Schmitt-Grohé and Uribe (2003), it depends on $\bar{D}_{t}$, the aggregate value of $D_{t}$ :

$$
\Psi_{t}=\bar{\Psi}+\tilde{\Psi}\left(e^{\bar{D}_{t}-\bar{D}}-1\right)
$$

The representative household maximizes the expected present discounted utility of consumption and labor effort. We assume GHH preferences following Greenwood, Hercowitz and Huffman (1988) for which the marginal utility of consumption is

$$
\lambda_{t}^{c}=\left(C_{t}-\kappa \frac{H^{\tau}}{\tau}\right)^{-\sigma}
$$


where $\kappa, \tau$, and $\sigma$ are parameters. Optimal labor supply is then given by:

$$
w_{t}=\kappa H_{t}^{\tau-1}
$$

The optimal foreign borrowing-lending policy is given by

$$
1=\beta^{h} E_{t} \frac{\lambda_{t+1}^{c}}{\lambda_{t}^{c}} \Psi_{t+1} R_{t+1}^{*}
$$

where $\beta^{h} \in(0,1)$ is the household's discount factor and $E_{t}($.$) is the conditional expectation$ operator.

Finally, capital accumulation is subject to adjustment costs:

$$
K_{t+1}=(1-\delta) K_{t}+X_{t}-\frac{\varphi}{2} K_{t}\left(\frac{K_{t+1}}{K_{t}}-1\right)^{2}
$$

where $0<\delta<1$ is the depreciation rate and $\varphi>0$ is a parameter giving the degree of adjustment costs. Then optimal investment is given by the dynamic equation:

$$
\begin{aligned}
& Q_{t}\left[1+\varphi\left(\frac{K_{t+1}}{K_{t}}-1\right)\right] \\
= & \beta^{h} E_{t} \frac{\lambda_{t+1}^{c}}{\lambda_{t}^{c}}\left[r_{t+1}^{K}+Q_{t+1}(1-\delta)+\varphi\left(\frac{K_{t+2}}{K_{t+1}}-1\right) \frac{K_{t+2}}{K_{t+1}}-\frac{\varphi}{2}\left(\frac{K_{t+2}}{K_{t+1}}-1\right)^{2}\right]
\end{aligned}
$$

This equation, as well as the previous ones, have standard interpretations.

For a given process for the price of capital $Q_{t}$, and given a process for $\Pi_{t}$, the preceding two equations determine the demand for investment. It is often assumed that domestic output can be split between consumption goods and new capital goods at no cost, so that $Q_{t}=1$ always, and that capital production yields no profits so that $\Pi_{t}=0$. In that case, (1)- (10) is a system of ten equations that suffices to determine the rest of the variables so far. 


\subsection{Finance and Production of New Capital Goods}

To depart from the usual approach, we assume that new capital goods $X_{t}$ are produced via a process subject to financial frictions. In equilibrium $Q_{t}$ will be variable and investment will reflect the dynamic supply of investment as well as demand. More importantly, those dynamic forces will interact with the behavior of alternative modes of corporate finance.

New capital goods are produced by "holdings", each of which manages a continuum of productive units ("branches" for short) indexed by $i \in[0,1]$. The representative holding arrives at period $t$ with some amount of equity $K_{t}^{f}$, inherited from the previous period. At the beginning of the period, each branch $i$ is charged with financing and executing a project of the same size, which takes $I_{t}$ units of the final good as input, and returns a random amount of new capital goods at the end of the period, as we will describe below. The size of the investment project, $I_{t}$, is chosen by the manager of the holding to maximize end of period profits. At the end of the period, successful branches return all their profits back to the holding manager. Also, as holdings are ultimately owned by households, a fraction of these profits are paid out every period as dividends.

Also at the beginning of the period, the holding's equity is split evenly between its branches, so that each of them receives $K_{t}^{f}$ (due to their unit mass). Every branch $i$ then faces an idiosyncratic shock $Z_{t}^{i}$ to its equity, which is a random variable with mean one, distributed i.i.d. across periods and time. This setting can be thought of as a situation in which there are nationwide corporations (holdings) that own units (branches) in different locations. The holding chooses a project design that has to be implemented by all branches. Each branch is given the same initial amount of equity money, but idiosyncratic, location-specific startup cost shocks imply that branches effectively start projects with equity $A_{t}^{i}=Z_{t}^{i} K_{t}^{f}$, distributed with the cumulative distribution function $G_{t}($.$) . Simple algebra shows that G_{t}(A)$ can be re-expressed as $G_{t}(A)=\Phi\left(\log a_{t}\right)$, where $a_{t}$ is the level $A$ normalized by the holding equity

$K_{t}^{f}$ (i.e. "per-unit of holding equity" level of $A$ ) and $\Phi($.$) is a time-independent cdf of$ 
$\log Z_{t}^{i}{ }^{13}$ This normalization will prove useful in the following discussion ${ }^{14}$

\subsubsection{Individual Projects}

Consider the problem of a branch which starts period $t$ with equity $A_{t}^{i}$. As mentioned, the branch manager takes the project size $I_{t}$ as given. For most firms in the distribution (except for a small fraction very far in the right tail of the distribution, discussed below) it will be the case that $I_{t}>A_{t}^{i}$. These firms will seek external financing in order to implement the investment project. As we are interested in foreign borrowing by emerging markets' firms, we assume that external financing in the model comes from abroad. As in HT, we allow for both direct and intermediated financing. Directly financed projects are not monitored and therefore can be associated with borrowing via bonds. Intermediated borrowing is subject to monitoring and can be associated with bank lending.

Specifically, investment projects are subject to moral hazard. If the branch manager has secured at least an amount $I_{t}$ of funds at the beginning of the period, she can invest them into a "good" project that yields $R I_{t}$ units of new capital with probability $p_{H}$ and zero with probability $1-p_{H}$. The manager can, alternatively, invest $I_{t}$ in a "bad" project, which reduces the probability of the successful outcome to $p_{L}<p_{H}$ but gives the manager a private benefit of size $B I_{t}$. Here $R, B, p_{H}$ and $p_{L}$ are some given parameters.

Branches can seek funds from foreign outside investors. Because, for tractability, contracts are settled within a period, and the rest of the world is included in the set of outside investors, it is appropriate to assume that outside investors are risk neutral and have a zero opportunity cost for funds. However, assuming that the good project has positive expected value but the bad project does not, outside investors will agree to lend only under a contract

\footnotetext{
${ }^{13} G_{t}(A)=\operatorname{Pr}\left\{A_{t}^{i} \leq A\right\}=\operatorname{Pr}\left\{\log A_{t}^{i} \leq \log A\right\}=\operatorname{Pr}\left\{\log Z_{t}^{i} \leq \log A-\log K_{t}^{f}\right\}=\operatorname{Pr}\left\{\log Z_{t}^{i} \leq \log a_{t}\right\}=$ $\Phi\left(\log a_{t}\right)$.

${ }^{14}$ The reason why the distribution of equity is not history-dependent is entirely for tractability. Otherwise one would have to keep track of the entire distribution of equity in the economy. This modeling choice, however, can be justified since the probability of success in a given period is exogenous and given by $p_{H}$, and all ICCs hold. Since every branch "behaves", every branch's ex post return is purely random and history-independent as well, therefore there is no reason to reward one branch more than another.
} 
that provides enough incentives to the branch manager not to undertake the bad project. Denoting by $R_{t}^{f, i}$ the payoff to the branch manager in case of project success, the necessary incentive compatibility constraint can be written as

$$
p_{H} R_{t}^{f, i} \geq p_{L} R_{t}^{f, i}+B I_{t}
$$

or

$$
R_{t}^{f, i} \geq \frac{B I_{t}}{\Delta}
$$

with $\Delta=p_{H}-p_{L}$

Also, for the branch to be able to finance the project by borrowing from the outside lenders, the amount borrowed must be $I_{t}-A_{t}^{i}$. Then, the expected payoff to the lenders must be at least as large, that is,

$$
p_{H}\left(Q_{t} R I_{t}-R_{t}^{f, i}\right) \geq I_{t}-A_{t}^{i}
$$

Combining the last two inequalities, it follows that the branch manager will be able to finance its project directly from outside lenders (i.e. via bonds sold abroad) only if it has enough equity: $A_{t}^{i} \geq \bar{A}_{t}$, where

$$
\bar{A}_{t}=I_{t}\left[1-p_{H}\left(R Q_{t}-\frac{B}{\Delta}\right)\right]
$$

It will be useful for the discussion that follows to normalize this cutoff by $K_{t}^{f}$, the aggregate level of holding equity:

$$
\bar{a}_{t}=i_{t}\left[1-p_{H}\left(R Q_{t}-\frac{B}{\Delta}\right)\right]
$$

\footnotetext{
${ }^{15}$ Since the branch is not the ultimate owner of the equity it operates and has to return the net revenue back to the holding at the end of the period, it may be asked why would then the incentive constraint apply to the branch. We assume here that the remuneration of the branch is performance based and proportional to the expected branch revenue by factor $x$. The incentive constraint of a branch can then be written as $x p_{H} R^{f}>x p_{L} R^{f}+B I$, which makes the constraint equivalent to the one in the main text and $x$ not separately identifiable from $B$.
} 
where $i_{t}=\frac{I_{t}}{K_{t}^{f}}$. Given $i_{t}, \bar{a}_{t}$ depends naturally on parameters such as $R$, as in HT. In our setting, $\bar{a}_{t}$ also depends on the price of capital: it falls if $Q_{t}$ increases. This will imply that more firms will be able to participate in bond financing, thus, in principle, increasing the supply of capital as $Q$ increases.

Consider now a branch $j$ for which $A_{t}^{j}<\bar{A}_{t}$ ? As in HT, we assume the existence of financial intermediaries or "banks". Banks start each period with some equity of their own that can be used for funding projects. More importantly, they also own a monitoring technology that allows them to reduce the branch manager's private benefit of the bad project from $B$ to $b<B$. However, using the monitoring technology entails a private cost $c I_{t}$ to a bank.

This implies that, for a branch $j$ to secure external funding with the participation of a bank, the bank's payoff if the project is successful, denoted by $R_{t}^{m, j}$, has to provide enough incentives for the bank to monitor:

$$
p_{H} R_{t}^{m, j}-c I_{t} \geq p_{L} R_{t}^{m, j}
$$

or

$$
R_{t}^{m, j} \geq \frac{c I_{t}}{\Delta} \equiv R_{t}^{m}
$$

Also, for a branch $j$ to convince a bank to participate in the project, it must offer the bank a return on its funds at least as large as what the banker would obtain elsewhere. Denoting the latter by $\beta_{t}$ and the bank's contribution to the project by $I_{t}^{m, j}$, the condition is that $p_{H} R_{t}^{m, j} \geq \beta_{t} I_{t}^{m, j}$. Although the contract is within a period, $\beta_{t}$ is greater than the market return (of one) to compensate the bank for the cost of monitoring but also, as we will see, because bank equity is scarce. This means that holding branches will never borrow more from bank's own equity than strictly necessary, so the condition must hold with equality, 
which combined with the previous relation gives

$$
I_{t}^{m, j}=\frac{p_{H} R_{t}^{m}}{\beta_{t}} \equiv I_{t}^{m}
$$

In this case, the participation of outside investors implies the incentive compatibility constraint $p_{H} R_{t}^{f, j} \geq p_{L} R_{t}^{f, j}+b I_{t}$, that is,

$$
R_{t}^{f, j} \geq \frac{b I_{t}}{\Delta}
$$

where $R_{t}^{f, j}$ denotes the payoff to the branch manager in case of project success.

Finally, for outside investors to recover the opportunity cost of their funds, their expected payoff must be at least as large as the amount they lend to the project. This can be written as:

$$
p_{H}\left(Q_{t} R I_{t}-R_{t}^{f, j}-R_{t}^{m}\right) \geq I_{t}-I_{t}^{m}-A_{t}^{j}
$$

In equilibrium, this inequality will be binding. ${ }^{16}$ As in the case of direct finance, one can show, by combining the previous three equations, that a branch $j$ will be able to finance its project via monitored finance if it has enough equity: $A_{t}^{j} \geq \underline{A}_{t}$, where

$$
\underline{A}_{t}=I_{t}\left[1-\frac{c p_{H}}{\beta_{t} \Delta}-p_{H}\left(R Q_{t}-\frac{b+c}{\Delta}\right)\right]
$$

Again, normalizing this equation by $K_{t}^{f}$ yields in turn

$$
\underline{a}_{t}=i_{t}\left[1-\frac{c p_{H}}{\beta_{t} \Delta}-p_{H}\left(R Q_{t}-\frac{b+c}{\Delta}\right)\right]
$$

The normalized version of the cutoff is handy, because $\Phi\left(\log \underline{a}_{t}\right)$ denotes the fraction of firms with no access to external finance in period $t$ and shows that this fraction is solely a function

\footnotetext{
${ }^{16}$ Note that, even in equilibrium, $R_{t}^{f, j}$ will not be constant across branches (i.e. we keep the $j$ subscript) because branches have different levels of equity $A_{t}^{j}$.
} 
of the normalized cutoff. We refer to this fraction of firms as "Category 1" firms. By analogy, the fraction of firms which borrow via banks ("Category $2 ")$ is given by $\Phi\left(\log \bar{a}_{t}\right)-\Phi\left(\log \underline{a}_{t}\right)$. Finally, the fraction of firms financing themselves through corporate bonds ("Category 3") is $1-\Phi\left(\log \bar{a}_{t}\right)$.

For the purpose of later analysis let us make an additional comment on the determination of the rate of return to bank equity $\beta_{t}$. In this setting, as in HT, the return to a banker for participating in a project must be large enough to induce monitoring. This requires that the payoff to the banker, $R_{t}^{m}=c I_{t} / \Delta$, exceed the opportunity cost of monitoring, which is just $c I_{t}$ (since $\Delta<1$ and the alternative rate of return is the intraperiod return of zero). Therefore, bankers earn an excess return for participating in investment projects. The assumption in HT, which we adopt here, is that bankers compete for such excess returns by providing equity $I_{t}^{m}$ to the projects. The rate of return $\beta_{t}$ then adjusts so as to equate the aggregate amount of bank equity thus offered to the available stock of bank equity at the beginning of the period, which will be denoted by $K_{t}^{m}$. In our formulation, $K_{t}^{m}$ is predetermined, so the rate of return on equity $\beta_{t}$ adjusts to reflect the scarcity of bank equity.

It may also be worth noting that the endogeneity of the return to bank equity $\beta_{t}$ implies that the responses of $\bar{A}_{t}$ and $\underline{A}_{t}$ to exogenous shocks are qualitatively different. From (11) it is apparent that shocks affect $\bar{A}_{t}$ only through their impact on the price of new capital $Q_{t}$ and project size $I_{t}$. In contrast, (12) tells that $\underline{A}_{t}$ responds to shocks not only through $Q_{t}$ and $I_{t}$, but also through $\beta_{t}$. Thus the nature of financing has important consequences for how the economy responds to external shocks such as to world interest rates. ${ }^{17}$

\footnotetext{
${ }^{17}$ To elaborate, suppose that $\beta_{t}$ were (counterfactually) some exogenous parameter $\bar{\beta}$. Then 11 and 12 ) imply that $\underline{A}_{t}$ would be the same as $\bar{A}_{t}$, but with the term $b+c(1-1 / \bar{\beta})$ in the former replacing the private benefit $B$ in the latter. Then indeed the responses of $\bar{A}_{t}$ and $\underline{A}_{t}$ to a shock in $R_{t}^{*}$ would be qualitatively the same. But this is not the case in our model, since $\beta_{t}$ is an endogenous variable rather than an exogenous parameter and therefore it fluctuates over the business cycle.
} 


\subsubsection{The Choice of Project Size}

The profits of a typical holding in period $t$ can then be written as:

$$
\begin{aligned}
\Pi_{t}^{f}= & p_{H} Q_{t} R I_{t}\left(1-G_{t}\left(\underline{A}_{t}\right)\right)+\int_{0}^{\underline{A}_{t}} A_{t}^{i} \mathrm{~d} G_{t}\left(A_{t}^{i}\right) \\
& -\int_{\underline{A}_{t}}^{\infty}\left(I_{t}-A_{t}^{i}\right) \mathrm{d} G_{t}\left(A_{t}^{i}\right)-p_{H} \frac{c I_{t}}{\beta_{t} \Delta}\left(G_{t}\left(\bar{A}_{t}\right)-G_{t}\left(\underline{A}_{t}\right)\right)\left(\beta_{t}-1\right)
\end{aligned}
$$

The first line expresses the holding's end of period revenue, the sum of expected payoff from investment projects plus the (zero) return from funds from branches that will not be able to finance their projects. The first term in the second line summarizes the market cost of external finance paid to outside investors. Noting that $\left(p_{H} c I_{t}\right) /\left(\beta_{t} \Delta\right)=I_{t}^{m}$, the last term captures the excess return to bank equity.

The holding chooses investment project size $I_{t}$ to maximize profits subject to (11) and (12), taking $Q_{t}$ and $\beta_{t}$ as given. After some manipulation, the first order optimality condition 18 can be written as:

$$
\begin{aligned}
& \left(p_{H} R Q_{t}-1\right)\left(1-G_{t}\left(\underline{A}_{t}\right)\right)-\left[\frac{c p_{H}}{\beta_{t} \Delta}\left(\beta_{t}-1\right)\right]\left(G_{t}\left(\bar{A}_{t}\right)-G_{t}\left(\underline{A}_{t}\right)\right) \\
= & \underline{A}_{t} g_{t}\left(\underline{A}_{t}\right)\left[p_{H} R Q_{t}-1\right]+\left[\bar{A}_{t} g_{t}\left(\bar{A}_{t}\right)-\underline{A}_{t} g_{t}\left(\underline{A}_{t}\right)\right] \frac{p_{H} c}{\beta_{t} \Delta}\left(\beta_{t}-1\right)
\end{aligned}
$$

where $g_{t}(A)$ is the density function associated with $G_{t}(.){ }^{19}$

The preceding equation together with 11 and 12 now determine $I_{t}, \underline{A}_{t}$, and $\bar{A}_{t}$. The interpretation of this condition is illuminating. The LHS can be seen as the expected increase in the surplus to the holding from a marginal increase in project size $I_{t}$. Each additional unit of initial investment has expected return $p_{H} R Q_{t}-1$, and is undertaken by $1-G_{t}\left(\underline{A}_{t}\right)$ branches. Part of that gain, however, is appropriated by the banks because the return on bank equity exceeds the market return (that is, if $\beta_{t}>1$ ). This is the second term in the LHS. The RHS

\footnotetext{
${ }^{18}$ For our discussion, we assume here that the first order condition identifies a maximum. Later, in the calibrated version of our model, we checked that the second order conditions for maximization do hold at the nonstochastic steady state.

${ }^{19} g_{t}(A)=\frac{\partial}{\partial A} G_{t}(A)=\frac{1}{A} \phi\left(\log A-\log K_{t}^{f}\right)$
} 
collects terms associated with the impact of an increase in $I_{t}$ on the distribution of branches. A larger $I_{t}$ implies an increase in $\underline{A}_{t}$ and, hence, a reduction of approximately $\underline{A}_{t} g_{t}\left(\underline{A}_{t}\right)$ producing units, implying a corresponding reduction in the holding's revenue of $p_{H} R Q_{t}-1$ per lost unit. Finally, $\bar{A}_{t}$ also increases, which means that approximately $\bar{A}_{t} g_{t}\left(\bar{A}_{t}\right)$ branches move from direct finance to bank finance. Since $\underline{A}_{t} g_{t}\left(\underline{A}_{t}\right)$ drop out from production, the number of branches resorting to bank finance increases by $\left[\bar{A}_{t} g_{t}\left(\bar{A}_{t}\right)-\underline{A}_{t} g_{t}\left(\underline{A}_{t}\right)\right]$, with each of them shifting profit towards banks by $\left(p_{H} c\right) /\left(\beta_{t} \Delta\right)\left(\beta_{t}-1\right)$. In other words, the fact that the LHS equals the RHS in (11) means that the optimal decision of the holding equalizes the net marginal revenue of undertaking one more unit of investment with its marginal cost.

\subsection{Market Clearing and Dynamic Equilibrium}

As discussed before, the return on the bankers' equity $\beta_{t}$ adjusts so that the bankers' participation in investment projects $I_{t}^{m}\left[G_{t}\left(\bar{A}_{t}\right)-G_{t}\left(\underline{A}_{t}\right)\right]$ adds up to available bank equity, denoted by $K_{t}^{m}$. This requires:

$$
K_{t}^{m}=I_{t}^{m}\left[G_{t}\left(\bar{A}_{t}\right)-G_{t}\left(\underline{A}_{t}\right)\right]=\frac{p_{H} c I_{t}}{\beta_{t} \Delta}\left[G_{t}\left(\bar{A}_{t}\right)-G_{t}\left(\underline{A}_{t}\right)\right]
$$

In turn, the equilibrium price of new capital goods, $Q_{t}$, must adjust to equate the demand for new capital goods to their supply:

$$
X_{t}=p_{H} R I_{t}\left[1-G_{t}\left(\underline{A}_{t}\right)\right]
$$

To finish specifying dynamics, we need to describe the laws of motion of the equity

variables $K_{t}^{m}$ and $K_{t}^{f}$. As a first approximation, we simply assume here that banks and holding companies have fixed dividend rates $1-\theta^{m}$ and $1-\theta^{f}$ respectively.

Hence the law of motion of $K_{t}^{m}$ is

$$
K_{t+1}^{m}=\theta^{m} \beta_{t} K_{t}^{m}
$$


and the law of motion of $K_{t}^{f}$ can be expressed as:

$$
K_{t+1}^{f}=\theta^{f} \Pi_{t}^{f}
$$

Now the eight equations (11)-(18) give $I_{t}, \underline{A}_{t}, \bar{A}_{t}, \beta_{t}, Q_{t}, \mu_{t}$ and the motions of $K_{t}^{m}$ and $K_{t}^{f}$. Together with (1)-10 and an assumption about the process for exogenous shocks, they complete the specification of the model.

\subsection{The Choice Between Direct versus Indirect Finance}

In spite of the complexity of the model, one can extract useful insight about the choice of direct versus indirect finance by studying the equilibrium conditions. Specifically, consider an unexpected increase of investment demand, which may be due to a favorable shock, specified in more detail later. Intuitively, in equilibrium, both the price and the quantity of investment must increase. Since the production of new capital goods requires external finance, and the equity of both holdings and banks is slow to adjust, the total amount of credit raised by the outside investors must increase, at least in the short run.

But we can say more than that. Increasing the production of new capital goods in this model requires a combination of a larger investment project size $I_{t}$ and of adjustments in the numbers of branches resorting to either direct or indirect finance. The latter is determined by the thresholds $\bar{A}_{t}$ and $\underline{A}_{t}$, given by $(11)$ and $(12)$.

In this situation, for the model to generate an increase in direct finance relative to indirect finance, as in the data, it must be the case that the threshold $\bar{A}_{t}$ fall relative to $\underline{A}_{t}$. This is, however, conditional on the shape of the assumed distribution of equity $G($.$) . We verify$ that this is indeed the case for the specific type of distribution that we use (see details below). But such a fall must reflect that bank finance has become relatively more expensive, as given by an increase in the return to bank equity $\beta_{t}$. More precisely, note that $(11)$ and $(12)$ imply 
that

$$
\frac{\bar{A}_{t}}{\underline{A}_{t}}=\frac{1-p_{H}\left(R Q_{t}-\frac{B}{\Delta}\right)}{1-\frac{c p_{H}}{\beta_{t} \Delta}-p_{H}\left(R Q_{t}-\frac{b+c}{\Delta}\right)}
$$

An increase in the demand for new capital goods raises the price of new capital $Q_{t}$ which, by itself, would raise the ratio. ${ }^{20}$ Increased demand also raises the return on bank equity $\beta_{t}$ and this must be the dominant force if the ratio is to fall.

The intuition is simple and illustrates the crucial roles of corporate equity and bank equity. As emphasized by HT, a branch will undertake a project of size $I_{t}$ if and only if it has enough equity to cover the shortfall between the unit cost of investment project, which is one, and the pledgeable income from the project, which is $p_{H}\left(R Q_{t}-\frac{B}{\Delta}\right)$ per unit of investment. The cutoff $\bar{A}_{t}$ is the value of equity which is just enough to cover that difference: that is what (11) says. Branches with equity less than $\bar{A}_{t}$ resort to their next best option, which is monitored finance. This reduces those branches' moral hazard problem (reflected in the fall in the parameter from $B$ to $b$ ) but entails two additional costs: monitoring costs reduce pledgeable income directly, as given by the term $c / \Delta$, but also banks appropriate part of the surplus since $\beta_{t}>1$, that is, since the rate of return on bank equity exceeds the (within period) market return (of one). Hence, when the price of capital increases, the fact that bank equity is scarce means that $\beta_{t}$ must increase in equilibrium. This reduces pledgeable income for bank-monitored projects (but not for projects with access to direct finance).

In this way, our model provides an economic explanation of the observed increase of bond issuance relative to bank loans in emerging markets. Falling world interest rates led to increased demand for new capital, raising the profitability of investment projects. In response, producers of new capital goods increased project size ( $I_{t}$ in our model) and adjusted the number of active branches and borrowing $\left(\bar{A}_{t}\right.$ and $\left.\underline{A}_{t}\right)$. Total credit then increased, predominantly through direct finance, since bank finance became more expensive (higher $\left.\beta_{t}\right)$.

\footnotetext{
${ }^{20}$ To see this, take $\operatorname{logs}$ and note that $\partial\left(\log \bar{A}_{t} / \underline{A}_{t}\right) / \partial Q_{t}=p_{H} R\left(1 / \underline{A}_{t}-1 / \bar{A}_{t}\right)>0$
} 
The above argument is somewhat loose in that it refers to the thresholds $\bar{A}_{t}$ and $\underline{A}_{t}$ only. Under our assumptions, however, the measure of branches resorting to either direct or indirect finance depends also on the shape of the distribution $G_{t}(A)$. Also, as we have seen, the thresholds depend on project size $I_{t}$. Therefore it will be useful to define measures of the total amounts borrowed via bonds or bank loans. For corporate bonds $C B_{t}$, a reasonable measure is

$$
C B_{t}=\int_{\bar{A}_{t}}^{I_{t}}\left(I_{t}-A_{t}^{i}\right) \mathrm{d} G_{t}\left(A_{t}^{i}\right)
$$

$C B_{t}$ is appropriate under the assumption that branches with access to direct finance put all their equity into their projects, and that branches with excess equity (those with $A_{t}^{i}>I_{t}$ ) do not issue bonds ${ }^{21}$ The corresponding measure for bank loans $B L_{t}$ is ${ }^{22}$

$$
B L_{t}=\int_{\underline{A}_{t}}^{\bar{A}_{t}}\left(I_{t}-I_{t}^{m}-A_{t}^{i}\right) \mathrm{d} G_{t}\left(A_{t}^{i}\right)+I_{t}^{m}\left[G_{t}\left(\bar{A}_{t}\right)-G_{t}\left(\underline{A}_{t}\right)\right]
$$

where the right-hand side indicates that bank loans are financed from a sum of deposits (first term) and banks' own equity (second term). The expressions for $C B_{t}$ and $B L_{t}$ emphasize that the shape of $G_{t}$ impacts both measures and their ratio. If $G_{t}$ were a Uniform cdf, of course, it would follow directly from the reasoning given above that an increase in the demand for new capital would raise the bond measure relative to the loans measure. As argued below, it is more realistic to assume that $G_{t}$ is not Uniform, however, and we will need to resort to numerical methods to examine the ratio. But the intuition given above remains valid.

\footnotetext{
${ }^{21}$ These firms pursue the investment project and allocate excess equity on the market at the riskless intratemporal interest rate (one). Notice that this allows the model to encompass the case of firms in emerging markets identified in some empirical studies that engage in carry trade activities (see Introduction).

${ }^{22}$ Here we are assuming that banks act as financial intermediaries. But, as HT note, an alternative interpretation might be that monitors provide certification services, which then allow branches in the indirect finance range to raise additional funds from outside investors. This would introduce some ambiguity in measuring bank loans. For concreteness, we stick to the financial intermediaries interpretation of the model.
} 


\section{Steady State and Calibration}

We calibrate the model at quarterly frequency. As we noted, our specification of households and production of final goods is fairly standard. Consequently, values for associated parameters are readily taken from the literature on small open economy models.

Our choices for $H, \sigma, \tau$ and $\alpha, \frac{C}{Y}, R^{*}, \tilde{\Psi}$, and $\varphi$ are taken from Fernández and Gulan (2015). We normalize the price of capital goods $Q$ and the total factor productivity parameter $\mathcal{A}$ to 1 . We then choose $\beta^{h}$ and $\delta$ to match the empirical ratios $\frac{X}{Y}=0.2$ and $\frac{K}{Y}=8$. The last value translates into capital stock being worth two years of output and is consistent with the data for Mexico collected by Kehoe and Meza (2012). The volatility and persistence parameters of the exogenous shocks to productivity are set to standard values as well. We calibrate the $R^{*}$ process to fit the data on ten year US bonds' interest rates deflated by the University of Michigan's survey-based inflation expectations. All calibrated parameters, normalizations and matched ratios are summarized in Table 1.

The second step of the calibration is more novel and involved. It concerns the parameters of the capital goods supply side, that is, of the holding companies. Recall that $\Phi(z)$ denotes the cdf of $z_{t}^{i}=\log Z_{t}^{i}$. We assume that is Normal with standard deviation $\sigma_{G}$ and mean $-\sigma_{G}^{2} / 2$ (which is necessary to ensure that the expectation of $Z_{t}^{i}$ is one). This implies that the distribution of equity within the holding, $G_{t}($.$) is log-normal, with mean K_{t}^{f}$. Log-normality is often assumed in macroeconomics (e.g. Bernanke, Gertler, and Gilchrist 1999) and in line with the literature on the size of firms (e.g. , Axell 2001, Quandt 1966).

We set the quarterly rate of return to bank equity $\beta=1.0364$, based on the World Bank's Global Financial Development Database (GFDD) for the United States (see Čihák et al., 2013). ${ }^{23}$ This automatically gives the value of banks' dividend parameter $\phi^{m}=\frac{1}{\beta}$. We calibrate $p_{H}=0.99$ following Meh and Moran (2010), which reflects a quarterly bankruptcy rate of $1 \%$. We then manually set $p_{L}=0.96$, the minimum value satisfying $\beta>\frac{p_{H}}{p_{L}}{ }^{24}$

\footnotetext{
${ }^{23}$ Recall that banks are foreign-based in the model because we attempt to explain the empirical dynamics of foreign bank loans.

${ }^{24}$ Keeping $p_{L}$ low relative to $p_{H}$ allows to widen the admissible parameter ranges for $c, b, B$ and $R$ in the
} 
At this stage one is left with equation (14), describing the first-order condition of the holding. Normalizing all terms by $K^{f}$ and simplifying, the equation reduces to an expression in only 6 unknowns: $c, b, B, \sigma_{G}, i=I / K^{f}$ and $R$. To pin down their values, we use five more independent restrictions.

The first target is the ratio of quarterly bank operating costs-to-bank assets, which we set to 0.78 percent guided by recent observations for the U.S. in the World Bank's GFDD. Because empirically monitoring costs constitute only a part of all banks' operating costs, this number constitutes in fact an upper bound for monitoring costs that one would like to target in the model.

Secondly, we try to match two leverage ratios. The first one is that of bank assets to bank equity (i.e. bank leverage) where we target the value 10.64, in line with the evidence reported in the World Bank's GFDD for U.S. commercial banks. The other is the representative holding's leverage: Fernández and Gulan (2015) report an average value of 1.71 for publiclytraded firms in EME-13.

Finally, we attempt to match two debt-related ratios akin to those presented in Figure 1. One is the median ratio of gross foreign bank loans stock to quarterly GDP, reported in the BIS for 5 selected Latin American countries (Brazil, Chile, Colombia, Mexico and Peru), approximately equal to 19.3 percent. The other, based on the same source of data, is the gross foreign corporate bond stock to quarterly GDP of 6.3 percent.

In addition to the six equations just listed, the unknowns $c, b, B, \sigma_{G}, i=I / K^{f}$ and $R$ must satisfy several inequalities 25 . Hence we choose values for those unknowns to minimize a weighted average of the differences between the model-generated and empirical ratios subject to the required inequalities. Details are given in the Appendix.

Table 2 presents the empirical targets of the ratios alongside those in the calibrated model calibration process and also implies a meaningful difference between the two probabilities.

${ }^{25}$ Specifically, it follows from HT that, for the model to be well behaved, the parameters $c, b, B$ and $R$ must satisfy: $0<\underline{A}<\bar{A}<I-I^{m}<I, b+c>B>b$. Also, the Lagrange multipliers associated with (11) and (12) must be positive. Finally, there are natural restrictions; for example, monitoring costs cannot be negative and the rate of return $R$ should be greater than 1 . Finally, for the case of log-normal distribution, the second-order condition of the holding that delivers a profit maximum is $\frac{1}{2}-\frac{\log \underline{a}}{\sigma_{G}^{2}}>0$. 
whereas Table 3 summarizes the financial parameters' values that deliver these targets. The overall match is satisfactory. We get very close to the chosen targets for bank leverage and corporate bonds-to-GDP ratio. We underestimate somewhat the volume of bank loans, but importantly, they are still over twice as large in the model than bonds, as it is the case in the data. While we underestimate the bank operating costs, as discussed previously, the empirical target should be only interpreted as an upper bound for bank monitoring costs because it reflects all banks' operating costs. The one dimension in which the match is not as close is the leverage of the holding: the target is 1.71 whereas the best we can generate with the model parameters is 4.76 .

\section{Dynamic Implications}

In this section we present the performance of the model over time. To explain the main mechanisms at work in the model, we start with the impulse responses. We then perform a simulation in which we feed into the model a series of interest rate shocks recovered from the data. This exercise shows that the model is qualitatively able to replicate the empirical facts presented in the introduction. Finally, we study how a change in structural financial parameters of the model affect the economy and its dynamics.

\subsection{Implications of Lower Interest Rates}

Figure 3 describes impulse responses to a one percentage point drop in the quarterly (nonannualized) world interest rate $R_{t}^{*}$. This exercise is intended to explore the response of the model to the fall in real interest rates observed since the start of the millennium.

As usual, lower world interest rates raise both the household's stochastic discount factor and the marginal utility of consumption. As a consequence, consumption, output, and hours increase for several periods (about 20 quarters in our calibration), reflecting the persistence 
of the $R_{t}^{*}$ shock ${ }^{26}$ Also as a consequence, households increase their demand for capital goods $X_{t}$. This is met, in equilibrium, with both an increase in the production of new capital goods and the price of capital $Q_{t}$.

The dynamic responses of investment projects and the mix of direct and indirect finance accord with the intuition presented earlier. Since the price of new capital increases, holding companies have an incentive to increase production. To do this, the size of the typical project relative to the holding's equity, $i_{t}=I_{t} / K_{t}^{f}$, increases for several quarters. Since $K_{t}^{f}$ is predetermined, the project size $I_{t}$ itself increases on impact and afterwards it is hump shaped.

To understand the responses of the quantities of bonds and loans the figure reports the responses of $\bar{a}_{t}=\frac{\bar{A}_{t}}{K_{t}^{f}}$ and $\underline{a}_{t}=\frac{\underline{A}_{t}}{K_{t}^{f}}$, i.e. thresholds normalized by $K_{t}^{f}$, denoted as "abar" and "aubar" in the figure, respectively. From (11) we know that the response of $\bar{a}_{t}$ is ambiguous, since the increase in $i_{t}$ raises it but the increase of $Q_{t}$ lowers it. The latter dominates in our calibration: on impact, $\bar{a}_{t}$ falls implying that the number of branches resorting to direct finance increases (these are labeled "Category 3 " branches). In contrast, $\underline{a}_{t}$ increases. As discussed before, this reflects not only the impact of higher $i_{t}$ and $Q_{t}$, but also an increase in the relative cost of bank finance reflected in the rising return to bank equity $\beta_{t}$. The latter occurs, as discussed, because bank equity is predetermined.

The figure shows that both bonds and loans increase on impact, although bonds increase by more, so that the $C B_{t} / B L_{t}$ ratio goes up. The ratio increases relative to its steady state level for about a year and a half, and then undershoots. The evolution of this ratio reflects the dynamics imparted by the accumulation of profits, which leads to increases in both the holding's equity $K_{t}^{f}$ and bank equity $K_{t}^{m}$. Both increase for about two years, which in turn supports more capital production and, therefore, bond financing and loan financing. Part of this increase can be attributed to the fact that the number of firms with access to external finance, i.e the extensive margin, increases. As a consequence, $Q_{t}$ drops relatively quickly.

\footnotetext{
${ }^{26}$ Output does not react on impact which reflects the key property of GHH preferences, namely the lack of income effect on the supply of labor.
} 
$\beta_{t}$ also falls sharply, reflecting both the fall in $Q_{t}$ as well as the accumulation of bank equity. The fall in $\beta_{t}$ means that bank finance becomes more attractive; this is reflected in the fact that $B L_{t}$ has a hump shaped response, while $C B_{t}$ is monotonic. This also explains why the $C B_{t} / B L_{t}$ ratio appears to be less persistent than investment projects.

Over time, the impact of the shock wanes, and all variables return to their steady state values. Overall, this experiment indicates that our model can replicate the recent observed increases in both direct and indirect finance, as the economy reacts to a fall in the world interest rate. In this sense, the model rationalizes the evidence presented in the introduction.

\subsection{A Simulation}

As a complement to the impulse response analysis of the previous subsection, we examine the predictions of the model when hit by a sequence of shocks to real interest rates akin to those observed in the data. For that purpose, we obtain the fitted residuals from an $\operatorname{AR}(1)$ process that we estimate on the real ex ante 10 year US bond rate. Then we feed these residuals as $R_{t}^{*}$ shocks into the model. The simulation period goes from 3Q 2004 until 4Q 2015. Figures 4 and 5 plot the results of this experiment.

The left panel of Figure 4 plots the total amount of corporate external debt implied by the model, i.e. the sum of stocks of corporate bonds $C B_{t}$ and bank loans $B L_{t}$, normalized to 100 for the first period of the simulation. The right panel plots the simulated paths of $C B_{t}$ and $B L_{t}$ separately. Qualitatively, the process of total debt tracks well the one observed in Figure 4. First, the simulation captures a rise of debt in the pre-Lehman period, then a reversal during the crisis in 2008-2009, followed by a vigorous recovery in the years 20102013. The simulation also mimics a stronger recovery of bond issuance in the post crisis, relatively to that of loans, which is a distinctive feature in the data presented in Figure 4. Quantitatively, from trough in 2009 to peak in 2013, the simulation captures half of the

increase in corporate debt observed in the data. However, it counterfactually predicts a considerable fall of debt in the last two years of the period considered, 2014-2015, whereas 
the data displays only a stagnation.

Finally, Figure 5 shows that the surge in debt issuance has been, according to the model, channeled to the real economy, mainly to productive investment, but also to consumption. This is qualitatively consistent with the empirically observed growth in capital accumulation reported in Caballero, Fernández and Park (2016) and Alfaro et al. (2016), as discussed in the Introduction.

This experiment exemplifies the model's view of how low interest rates may help explaining the outburst of corporate external debt in emerging markets. Evidently however, factors other than low interest rates may have also contributed to the considerable growth in debt in these economies, and indeed one of them, commodity prices, will be the subject of a later section. But before we turn to that, we explore the role and impact of some of the deep parameters of the model.

\subsection{The Impact of Financial Frictions}

The values of the parameters of the model, especially those related to financial frictions can be thought of as proxies for a country's level of financial development. We focus on monitoring costs and the private benefit from moral hazard.

\subsubsection{Monitoring Costs}

Suppose that monitoring costs $c$ are one third higher than in the benchmark calibration, while all other parameters of the model are kept at their benchmark values. The corresponding steady state is reported in the third column of Table 4.

Intuitively, a larger $c$, by making monitoring more costly, reduces the size of investment projects, so that aggregate investment in physical capital $X$ should go down and the price of capital $Q$ should go up. In turn, the steady state levels of capital, output, and consumption

all should go down. The table shows that all of these implications are borne out, although the magnitudes are small. 
More noticeably, bank loans $B L$ fall in the steady state. This is not surprising, since a larger monitoring cost not only induces less total borrowing, but also a switch away from bank finance. To put it in terms of our previous discussion, a larger $c$ is associated with a lower project size $i$ and a higher price of capital $Q$. Looking at (11) and (12), both $i$ and $Q$ have the same effect on $\bar{a}$ and $\underline{a}$, given that they affect pledgeable income in the same way. However, the higher value of $c$ has an additional, direct effect on $\underline{a}$, reflecting that larger monitoring costs reduce pledgeable income of monitored projects. So it must be the case that, for given $i$, the ratio $\bar{A} / \underline{A}$ must fall.

The switch away from bank finance explains why corporate bonds, $C B$, increase in the steady state. This reflects the fact that the effect of more branches moving into Category 3 (direct finance) dominates the fact that each branch borrows less. (since project size $I$ falls). In contrast, the fall in $B L$ is explained by the fall in project size, since the measure of branches moving to Category 2 (bank finance) actually increases.

To see how the model's dynamics change when $c$ is higher, Figure 6 plots impulse responses to a one percentage drop in the world interest rate $R_{t}^{*}$ in the benchmark case (solid/black) and the counterfactual case of higher $c$ (dashed/red). In the counterfactual case, the response of the real variables is dampened relative to the benchmark. In other words, increasing the cost of monitoring puts sand in the wheels of the mechanism by which foreign interest rate shocks translate into movements in economic activity. This can be clearly seen in the responses of aggregate investment in physical capital $X_{t}$, which increases in the counterfactual by much less relative to the benchmark, thus making the price of new capital goods $Q_{t}$ go upwards by more.

The explanation for the dampening can be traced back to the responses of the holding's debt, particularly that channeled trough banks. Indeed, total loans not only decrease in the steady state (as argued before), but their response to a drop in interest rates is less vigorous when $c$ increases than in the benchmark. This comes intuitively from the fact that bank credit is more costly. Note also that the response of bond finance is stronger relative to the 
benchmark, increasing the bond to loan ratio.

Another direct consequence of higher monitoring costs and the associated reduction of the demand for bank loans is the reduction of banks' revenue. Consequently, bank equity accumulation is relatively more sluggish than in the benchmark, which inhibits banks lending later on. This has also negative implications for equity buildup of the holding companies which, likewise, experience a relatively slower pace of equity accumulation. Lastly, household income is affected by this slower equity buildup of the holding insofar as the dividends as smaller than in the benchmark, reducing the extent to which consumption rises following the shock.

\subsubsection{Private benefits}

Suppose now that the private benefit $B$ associated with moral hazard is ten percent smaller relative to the benchmark. This may capture an increase in transparency in the private sector, less corruption, or a stronger rule of law.

The impact on the steady state is given in the last column of Table 4. Intuitively, one should expect a lower $B$ to lead to more investment, capital, output, and consumption, as well as a lower price of new capital goods. Again, these predictions are confirmed by the table, although the magnitudes are small.

Lower private benefits also favor direct finance over bank finance. The table shows that, accordingly, the measure of branches obtaining direct finance (Category 3) increases, and so does the amount of bonds $C B$. In contrast, the measure of branches with bank loans falls; this reflects both the increase in project size $I$ as well as the fall in the price of new capital goods $Q$. As a consequence, bank loans $B L$ fall in the steady state.

Figure 7 describes the impulse responses to a one percentage drop in the world interest rate $R_{t}^{*}$ in the benchmark (solid/black) and the counterfactual case (dashed/red) of lower $B$. Perhaps the most remarkable feature of the counterfactual dynamics is reflected in the evolution of the holding's debt. The quantity of bonds increases by more relative to the 
benchmark while the opposite occurs with bank loans. Consequently, the bond-to-loan ratio increases more on impact, (in addition to the previously discussed increase in the steady state).

However, this change in the composition of debt does not translate into a stronger increase in the reaction of the real variables (e.g., output, aggregate investment, consumption) following an interest rate shock. If anything, the opposite occurs, i.e. the reactions of real variables are now dampened relative to the benchmark case when $B$ was higher. The key to understand this is that, even with a lower $B$, the reaction of holdings to an increase in the price of capital is restricted by their equity, and also by equity of banks (which determines the cost of bank finance). The accumulation of both types of equity is slower than in the benchmark, which dampens the impulse responses.

The observations in this subsection and the previous one raise the interesting possibility that the observed increase in bond financing relative to bank financing may reflect changes in the financial technology, as given by an increase in $c$ or a fall in $B$. Such changes, in turn, would not increase the economy's sensitivity to external shocks: here the responses of investment and aggregate demand to interest rate shocks are, if anything, smoother when $c$ is higher or $B$ lower. This should not be too surprising in the context of our model, because holdings do take advantage of an additional margin of adjustment when facing shocks. On the other hand, this perspective provides an interpretation of the data reviewed in the introduction that is more optimistic than that of Shin (2013) and others. ${ }^{27}$

\section{Bonds, Loans, and Commodity Prices}

While world interest rates appear to be the obvious suspects in accounting for the observed dynamics of bonds and loans, emerging economies have been hit by other external shocks. Most noticeably, drastic fluctuations in commodity prices have been at center stage, as

\footnotetext{
${ }^{27}$ As mentioned in a previous footnote, Shin's (2013) perspective is largely grounded on the possibility of currency mismatches. Our model does not feature mismatches, so it is not suitable to evaluate such perspective.
} 
illustrated by Figure 8. The left panel of the figure plots the evolution of the price index for the three broadest categories of commodity goods, raw agricultural products, metals and fuels, since the 1990s. It shows a remarkable increase in the volatility of the prices of all three categories since the mid 2000s. ${ }^{28}$

The right panel of Figure 8 uses country-specific commodity price indices computed for Brazil, Chile, Colombia and Peru, all net commodity exporters, and compares the indices with the Latin American EMBI spread. The plot shows that the four price indices were strongly correlated with each other, and also endured a marked increase in their volatility since the mid 2000s. At that time foreign financing is these countries also began increasing; this was expressed by a remarkable negative comovement between commodity prices and country spreads, which is shown in the figure. That periods of booming commodity prices have coincided with low interest rate spreads on country debt has been observed not only for the four countries here but for commodity-exporting emerging economies in general ${ }^{29}$

These drastic fluctuations in the prices of commodities exported by emerging economies has motivated a recent literature on their business cycle implications as well as the appropriate monetary and fiscal policy responses. 40 The literature, however, has largely ignored the related issue of how commodity prices and financial flows may be related. Specifically, can favorable shocks to commodity prices explain the stylized patterns of bond and bank financing in emerging economies? In this section we outline an extension of our basic model that provides a positive answer. More generally, the model suggests interesting links between commodity prices and the type of capital flows to emerging economies 31

\footnotetext{
${ }^{28}$ The three price indices are computed by the IMF and are publicly available on the web. The figure presents a smoothed transformation of the original series using a centered rolling moving average of 6 months.

${ }^{29}$ Country-specific commodity prices come from Fernández et al. (2015), who calculated them combining the spot prices of 44 distinct commodity goods sold in international markets with country-specific shares of each of these commodities in total commodity exports. This work computes country-specific price indices for a large pool of emerging economies and quantifies the (strong) degree of comovement between them. It also provides more systematic evidence between country-specific commodity prices and measures of sovereign and corporate spreads of international debt issued by emerging economies.

${ }^{30}$ See e.g. Fernández et al. (2015) and the studies in Caputo and Chang (2015).

${ }^{31}$ Recent works have studied the amplification mechanism of spreads that react to changes in commodity prices within a quantiative general equilibrium (see Fernández et al., 2015 and Shousha, 2016). Others have tried to provide microfoundations for movements in spreads following changes in commodity prices within a
} 
Doing full justice to this issue would require a separate paper, in our view; our treatment here is intended only to illustrate the main connections, as well as to reinforce the intuition of our model of alternative modes of finance. So, following Catao and Chang (2013), among others, we add a simple commodity export sector ("mining") of competitive "mines" to the benchmark model analyzed before. The representative mine produces and exports a commodity ("copper") whose world price (relative to traded final goods) is exogenous and denoted by $P_{t}^{C}$. It is assumed that $P_{t}^{C}$ follows an $\operatorname{AR}(1)$ process:

$$
P_{t}^{C}=\left(1-\rho_{C}\right) \bar{P}^{C}+\rho_{C} P_{t-1}^{C}+\varepsilon_{t}^{C}
$$

where $\bar{P}^{C}$ is the real steady state price of copper and $\varepsilon_{t}^{C}$ are normally distributed iid shocks with mean 0 and variance $\sigma_{C}^{2}$.

Production takes only capital, and the production of the typical mine is:

$$
Y_{t}^{C}=A^{C}\left(K_{t}^{C}\right)^{\alpha_{C}}
$$

where $Y_{t}^{C}$ denotes copper output and $K_{t}^{C}$ the copper mine's capital. In addition, $\alpha_{C}$ and $A^{C}$ are constants.

The mine's only cost is accumulation of new capital $X_{t}^{C}$, which governs the evolution of mining capital. For simplicity, we assume that the adjustment costs are similar to those of households, although with possibly different coefficients:

$$
K_{t+1}^{C}=\left(1-\delta^{C}\right) K_{t}^{C}+X_{t}^{C}-\frac{\varphi^{C}}{2} K_{t}^{C}\left(\frac{K_{t+1}^{C}}{K_{t}^{C}}-1\right)^{2}
$$

The profits of a typical mine are then given by

$$
\Pi_{t}^{C}=P_{t}^{C} A^{C}\left(K_{t}^{C}\right)^{\alpha_{C}}-Q_{t} X_{t}^{C}
$$

financial accelerator framework (Beltran, 2015; González et al., 2015). None of these works, however, have studied the type of capital inflows into emerging economies and commodity prices. 
In the preceding expression we have assumed that the mining sector uses the same capital goods as the non-mining sector, and buys them at the same price $Q_{t}$. Profits increase with the commodity price, and fall with the price of new capital $Q_{t}$.

Finally, we assume that mines are wholly owned by the representative household. As a consequence, the mine's problem is to choose a dynamic investment plan that maximizes the present value of its profits, with the discount factor given by the household's marginal utility of income. This results in an adjustment equation of mining capital which is similar to the one for non-mining capital:

$$
\begin{aligned}
& Q_{t}\left[1+\varphi^{C}\left(\frac{K_{t+1}^{C}}{K_{t}^{C}}-1\right)\right] \\
= & \beta^{h} E_{t} \frac{\lambda_{t+1}^{c}}{\lambda_{t}^{c}}\left\{r_{t+1}^{C}+Q_{t+1}\left[\left(1-\delta^{C}\right)+\varphi^{C}\left(\frac{K_{t+2}^{C}}{K_{t+1}^{C}}-1\right) \frac{K_{t+2}^{C}}{K_{t+1}^{C}}-\frac{\varphi^{C}}{2}\left(\frac{K_{t+2}^{C}}{K_{t+1}^{C}}-1\right)^{2}\right]\right\}
\end{aligned}
$$

where

$$
r_{t}^{C}=\alpha_{C} P_{t}^{C} A^{C}\left(K_{t}^{C}\right)^{\alpha_{C}-1}
$$

is the return on mining capital. Note that it increases with the commodity price.

The addition of the commodity sector requires two further amendments to the baseline model. First, the household's budget constraint 4 must include profits from this sector, $\Pi_{t}^{C}$. And second, since total new capital is now $X_{t}+X_{t}^{C}$, the market clearing condition for aggregate investment 16 becomes

$$
X_{t}+X_{t}^{C}=p_{H} R I_{t}\left[1-G_{t}\left(\underline{A}_{t}\right)\right]
$$

Calibrating the extended model involves choosing the parameters of the mining production function, $\alpha_{C}$ and $A^{C}$, a depreciation rate for mining capital $\delta^{C}$, the capital adjustment parameter $\varphi^{C}$, and the parameters in the process for the world price of commodities, $P^{C}$. In a similar specification to ours, Fornero et al. (2014) calibrate the capital share parameter in the production function of the commodity sector to 0.31 , using available data of physical 
capital from Codelco, the main copper producing company in Chile. Since this is almost the same as the capital share $\alpha=0.32$ of the baseline model, we just set $\alpha_{C}=\alpha=0.32$. Likewise, we set $\delta^{C}$ and $\varphi^{C}$ at the same levels as for their counterparts in the non-commodity sector. The two parameters in the process of the commodity price are set to $\rho_{C}=0.73$ and $\sigma_{C}=0.063$ following Fernández et al. (2015) who estimated an AR(1) process using country-specific commodity prices for various emerging economies that are net commodity exporters. Finally, we choose $A^{C}$ and adjust the nonstochastic steady state value of $\mathcal{A}_{t}$ so that, in the steady state, the total amount of aggregate investment in the model with commodities, $X+X^{C}$, equals the amount of new capital in the model without commodities; and also so that the value of mining output as a fraction of total home output is equal to 13.36 percent. The latter figure is the average of the commodity production to GDP ratio for Brazil, Chile, Colombia and Peru using estimates from Fernández et al. (2015).

Figure 9 presents impulse responses to a one percent favorable shock to commodity prices, $P^{C}$. Intuitively, one would expect an exogenous increase in the commodity price to raise profitability in the export sector, increasing investment and capital accumulation there, and also lead to increased consumption. The impulse responses are indeed consistent with such expectations. Total investment increases, and the price of capital $Q$ jumps up. Note, however, that investment in the non-commodities sector falls on impact. This is not too surprising given the increase in $Q$, and is reminiscent of "Dutch Disease" models.

The increase in total investment demand and the price of capital lead to by now familiar effects on the capital goods production side, as well as the behavior of bonds and loans. As in the baseline model, both bonds and loans increase, with the bonds to loans ratio increasing over its steady state value for about a year. Again, two forces are key: the increase in capital goods production leads to an expansion of both modes of finance; at the same time, the return to bank equity goes up, which makes bank finance relatively more costly to holdings and provides an incentive to switch from loans to bonds.

We see, therefore, that the dynamic behavior of bonds and loans in emerging economies 
can be a response to improvements in the prices of those countries' main export goods. Also, the mechanism by which such shocks affect bonds and loans when we add commodities to the model is quite similar to the one in the baseline model. In that sense, the analysis of this section complements and reinforces the insights from our specification of the supply of new capital goods.

The model presented in this section can and should, of course, be extended in several plausible directions. Also, one may want to investigate whether commodity prices are a better (or worse) candidate than world interest rates in accounting for the observed dynamics in the data; or whether the two kinds of shocks have reinforced each other in that regard. These extensions are, nevertheless, beyond the scope of the present paper.

\section{Final Remarks}

One of the most important macroeconomic developments in emerging economies in recent years has been the considerable increase in their reliance on foreign financing. This has led to a rise in the stock of international debt and has generated a lively debate about its desirability. A benign view postulates that this is a natural response to favorable external conditions and relatively favorable investment prospects in these countries. According to a less optimistic view, reminiscent of previous crises in emerging economies, larger foreign liabilities are dangerous and place these countries in a precarious position. A novelty, however, of this increase in foreign debt comes from the fact that most of it has been linked to private corporate debt, mainly in the form of direct bond issuance.

To shed light on these new developments from a theoretical perspective, we have built a tractable and intuitive dynamic model for a small open economy with endogenous determination of direct versus indirect finance. The endogenous financing choice is modeled from first principles under the presence of dual moral hazard (on the part of corporates as well as banks) using the seminal static model of Holmström and Tirole (1997) as a point of 
departure.

The model offers an intuitive economic explanation of the joint dynamics of bonds and bank loans in the data. Exogenous forces, in the form of low world interest rates or high commodity prices, increase the demand for capital goods, raise their relative price and firms' profitability. For a given level of corporate equity, this raises the pledgeable income and allows for growth in both corporate bonds and bank loans stocks. At the same time, however, the return to the equity of the banking sector goes up, reflecting its scarcity and slow pace of adjustment. Hence bank finance becomes relatively more costly than direct finance and, accordingly, the ratio of corporate bonds to bank loans goes up.

This analytical setup allows therefore to rationalize the benign view of the increase in bond issuance in foreign capital markets by corporates in emerging markets during the period of low global interest rates and high commodity prices. This holds insofar as corporates have taken advantage of an additional margin of adjustment (bond issuance) when facing shocks. The model, however, should not be viewed as evidence for this benign view, as it has relied on several strong assumptions that prevent a normative analysis. Most notably, it does not feature currency mismatches, so it is not suitable to evaluate the potential balance-sheet effects associated with fluctuations in exchange rates. Also, as it assumes that corporate borrowing is solely for productive purposes, it does not incorporate the possibility of arbitrage and carry trade that some empirical evidence suggests.

We have also made some further simplifying assumptions for tractability that future research ought to relax. In particular, we have assumed that the distribution of equity across investing branches is given by exogenous idiosyncratic shocks. We did so to ensure that the distribution of equity changes over time only through its first moment $K_{t}^{f}$. Relaxing it would be computationally hard although would allow us to understand the intertemporal interaction between the distribution of firms and their borrowing needs. Finally, we have assumed that investment projects and their financing, are all resolved within the period. This simplifies the analysis, but loosens the mapping between the model's variables and the 
empirical ones.

\section{References}

[1] Adrian, T, P. Colla, H. S. Shin, 2012. "Which Financial Frictions? Parsing the Evidence from the Financial Crisis of 2007-9", National Bureau of Economic Research, No. 18335. (also NBER Macroeconomics Annual, 2012, Vol. 27)

[2] Aguiar M., and G. Gopinath, 2007. "Emerging Market Business Cycles: The Cycle Is the Trend", Journal of Political Economy, University of Chicago Press, vol. 115, pages 69-102.

[3] Aikman, D., and M. Paustian, 2006. "Bank capital, asset prices, and monetary policy", Bank of England, Working Paper 305.

[4] Alfaro, L., G. Asis, A. Chari, U. Panizza, 2016. Lessons Unlearned? Corporate Debt in Emerging Markets. Mimeo

[5] Axtell R. L., 2001. "Zipf Distribution of U.S. Firm Sizes", Science, vol. 293, pp.18181820

[6] Bastos, F. R., Kamil, H., Sutton, B., 2015. Corporate financing trends and balance sheet risks in Latin America: taking stock of "The Bon(d)anza". IMF Working paper No. WP $/ 15 / 10$

[7] Bernanke, B., M. Gertler, and S. Gilchrist, Simon, 1999. "The financial accelerator in a quantitative business cycle framework", Handbook of Macroeconomics, in: J. B. Taylor \& M. Woodford (ed.), Handbook of Macroeconomics, edition 1, volume 1, chapter 21, pages 1341-1393, Elsevier.

[8] Besanko, D. and G. Kanatas, 1993. "Credit Market Equilibrium With Bank Monitoring and Moral Hazard", Review of Financial Studies 6 (1), 213-232. 
[9] Bolton, P. and D. S. Scharfstein, 1996. "Optimal debt structure and the number of creditors", Journal of Political Economy, 1-25.

[10] Bruno V. and H.S. Shin, 2015. Global dollar credit and carry trades: a firm level analysis. BIS WP No. 510

[11] Caballero J., A. Fernández, J. Park, 2016. "On Corporate Borrowing, Credit Spreads and Business Cycles in Emerging Economies. An Empirical Investigation", Mimeo

[12] Caballero J., U. Panizza, A. Powell, 2016. The Second Wave of Global Liquidity: Why Are Firms Acting Like Financial Intermediaries. BID WP No. 641

[13] Caputo, R. and R. Chang, eds., "Commodity Prices and Macroeconomic Policy ", Central Bank of Chile Series on Central Banking, Analysis, and Economic Policies, 2016

[14] Chen, N.-K., 2001. "Bank net worth, asset prices, and economic activity", Journal of Monetary Economics 48, 415-436

[15] Čihák M., A. Demirgüč-Kunt, E. Feyen, R. Levine, 2013. "Financial Development in 205 Economies, 1960 to 2010", National Bureau of Economic Research, Inc., NBER Working Papers 18946, April

[16] Crouzet N., 2015. Aggregate Implications of Corporate Debt Choices, Mimeo, Kellogg School of Management, Northwestern University, April

[17] De Fiore F. and H. Uhlig, 2011. "Bank Finance versus Bond Finance", Journal of Money, Credit and Banking, Blackwell Publishing, vol. 43(7), pages 1399-1421, October.

[18] De Fiore, F. and H. Uhlig, 2015. "Corporate debt structure and the financial crisis", ECB-WP 1759 (JMCB Forthcoming).

[19] Denis, D. and V. Mihov, 2003. "The choice among bank debt, non-bank private debt and public debt: Evidence from new corporate borrowings", Journal of Financial Economics. 
[20] Diamond, D. W., 1991. "Monitoring and reputation: the choice between bank loans and directly placed debt", Journal of political Economy, 689-721.

[21] Fernández A., and A. Gulan, 2015. "Interest Rates, Leverage, and Business Cycles in Emerging Economies: The Role of Financial Frictions", American Economic Journal: Macroeconomics, American Economic Association, vol. 7(3), pages 153-88, July.

[22] Fernández A., M. Klein, A. Rebucci, M. Schindler, M. Uribe, 2015. "Capital Control Measures: A New Dataset", NBER Working Paper No. 2097

[23] Gozzi, J. C., Levine R., Schmukler, S. L., 2010. Patterns in international capital raisings. Journal of International Economics 80, 45-57.

[24] Greenwood, J., Z. Hercowitz, G. Huffman, 1988. "Investment, Capacity Utilization, and the Real Business Cycle", American Economic Review, American Economic Association, vol. 78(3), pages 402-17, June.

[25] Holmström, B. , and J. Tirole, 1997. "Financial Intermediation, Loanable Funds, and the Real Sector", The Quarterly Journal of Economics, MIT Press, vol. 112(3), pages 663-91, August.

[26] Kehoe, T. and F. Meza, 2012. "Catch-up growth followed by stagnation: Mexico, 19502010", Working Papers 693, Federal Reserve Bank of Minneapolis.

[27] Meh, C. and K. Moran, 2010. "The role of bank capital in the propagation of shocks", Journal of Economic Dynamics and Control, vol. 34(3), 555-576.

[28] Neumeyer, P. A., and F. Perri, 2005. "Business cycles in emerging economies: the role of interest rates", Journal of Monetary Economics, Elsevier, vol. 52(2), pages 345-380, March. 
[29] Powell A., 2014. "Global Recovery and Monetary Normalization: Escaping a Chronicle Foretold?", 2014 Latin American and Caribbean Macroeconomic Report, Inter-American Development Bank, Washington DC, March

[30] Quandt, R., 1966. "On the Size Distribution of Firms", American Economic Review, vol. 56 , pp. $416-432$

[31] Rajan, R. G., 1992. "Insiders and outsiders: The choice between informed and arm'slength debt", The Journal of Finance 47 (4), 1367-1400.

[32] Repullo, R. and J. Suarez, 2000. "Entrepreneurial moral hazard and bank monitoring: A model of the credit channel", European Economic Review, vol. 44(10), 1931-1950

[33] Schmitt-Grohé, S. and M. Uribe, 2003. "Closing small open economy models", Journal of International Economics, Elsevier, vol. 61(1), pages 163-185, October

[34] Shin, H., 2013. "The Second Phase of Global Liquidity and Its Impact on Emerging Economies", Mimeo, Princeton University

[35] Turner, P. 2014. "The Global Long-Term Interest Rate, Financial Risks and Policy Choices in EMEs", BIS Working Paper No. 441. Monetary and Economic Department, Bank for International Settlements, Basel, Switzerland. 
Figure 1: Stock of foreign corporate debt in Latin America
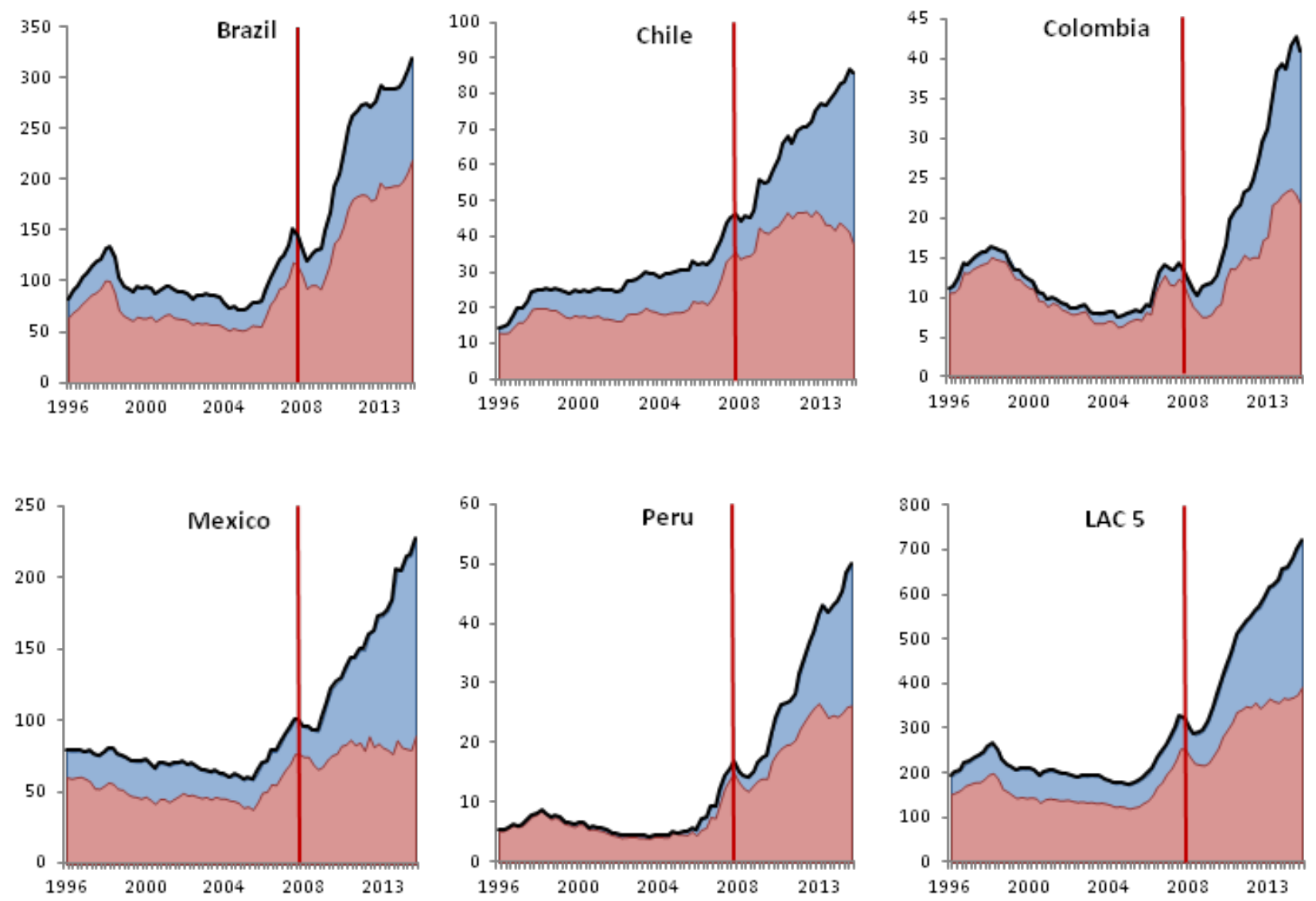

Notes: Units are billion USD. Red (bottom) areas indicate the stock of outstanding bank loans and blue (top) areas indicate outstanding corporate bonds, both measured on residence basis. Vertical lines indicate the collapse of Lehman Brothers. Sources: Powell (2014) and BIS. 
Figure 2: Global Interest rates for Emerging Economies.

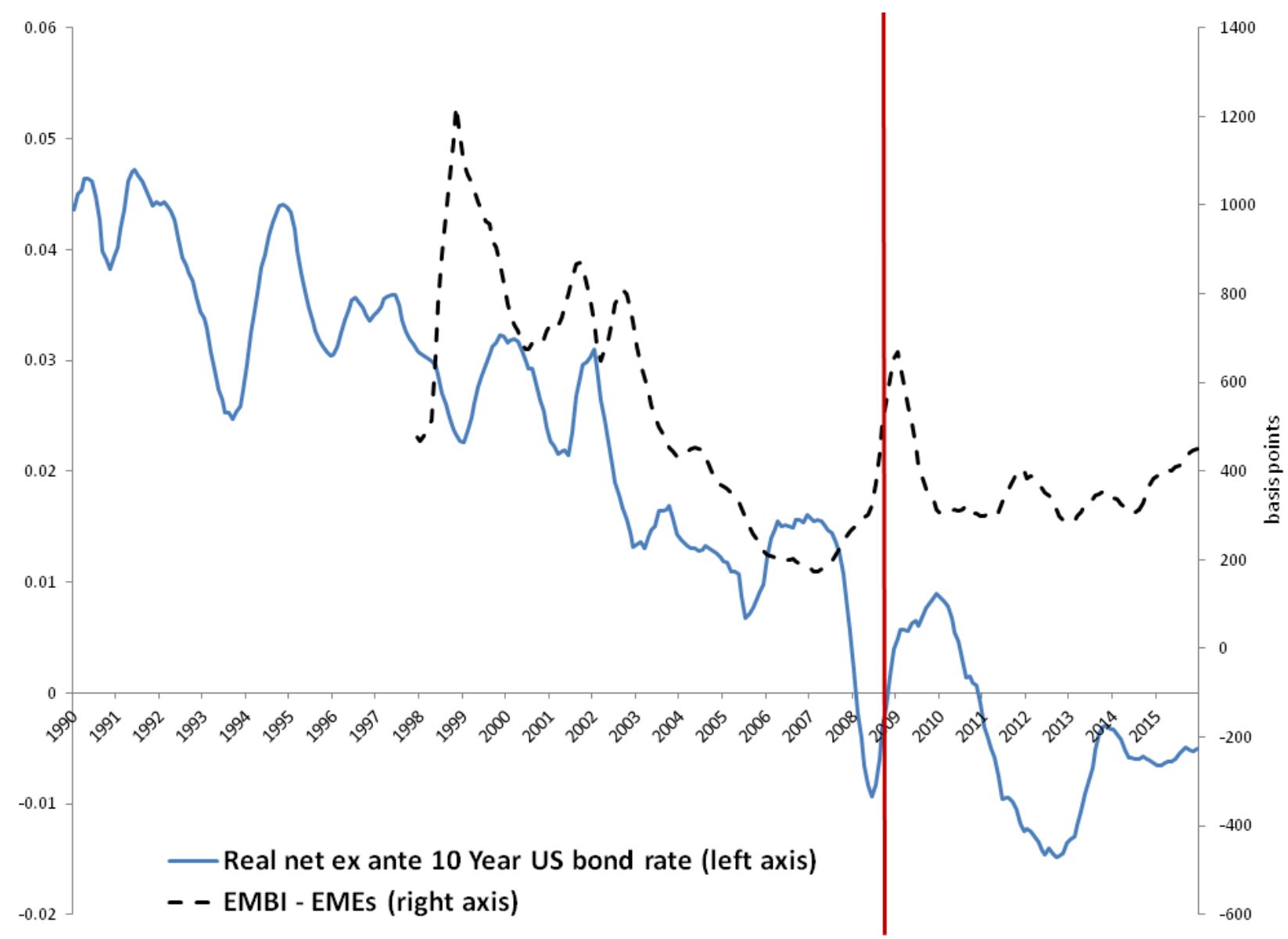

Notes: Vertical line indicates the collapse of Lehman Brothers. The 10 Year U.S. bond rate is deflated using the University of Michigan Consumer Survey Inflation Expectations. EMBI spread is the J.P. Morgan Emerging Markets Bond Index. Sources: Bloomberg and University of Michigan. 
Figure 3: Impulse responses to one percentage point drop in $R^{*}$.
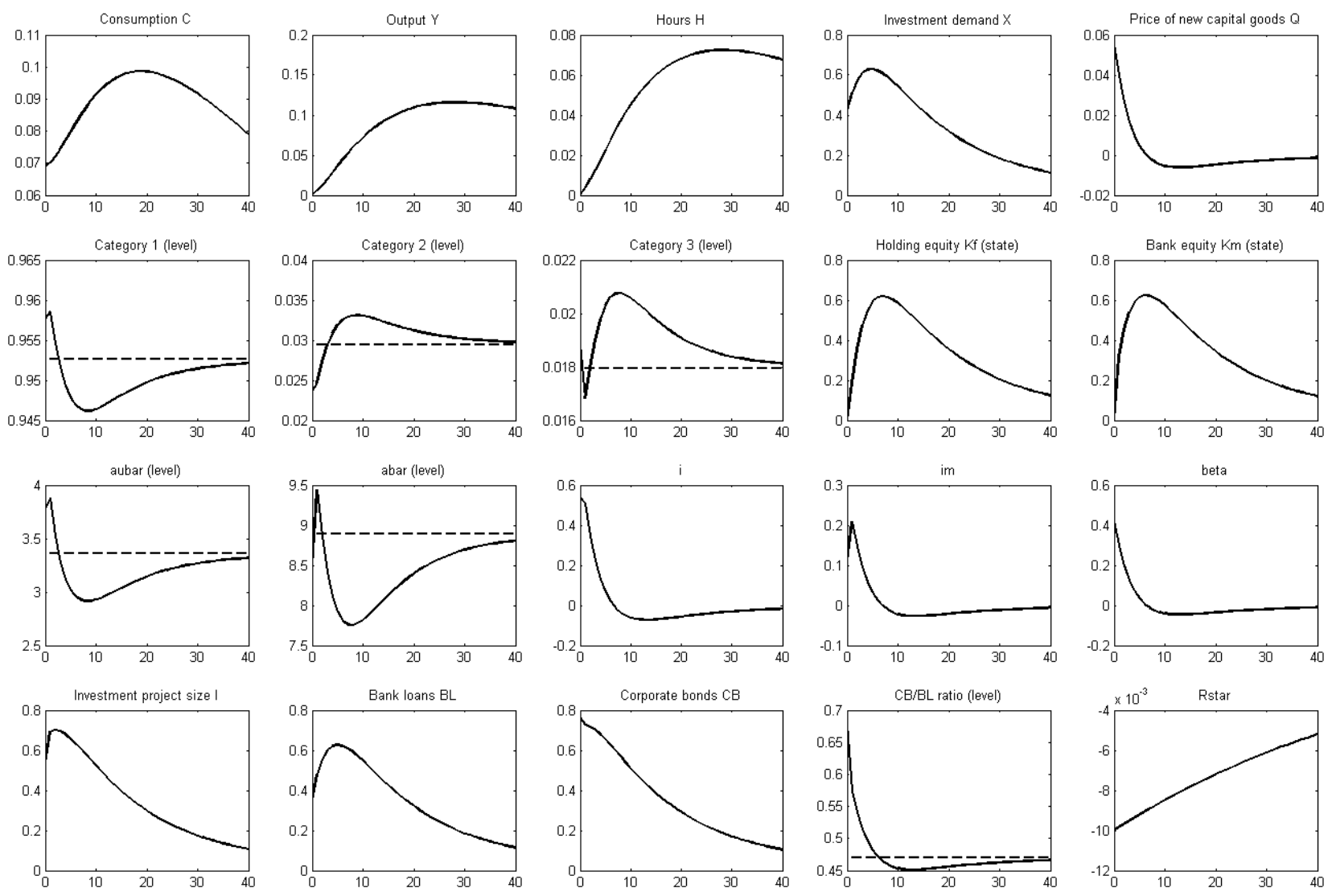

Notes: All variables plotted are percentage deviations from the non-stochastic steady state, unless indicated that they are in levels. This applies to the IRFs for the three categories, cutoffs and the bond-to-loan ratio. Horizontal dashed lines denote steady state values of the variables plotted in levels. 
Figure 4: Simulation of debt following $R^{*}$ shocks, 3Q 2004 - 4Q 2015.

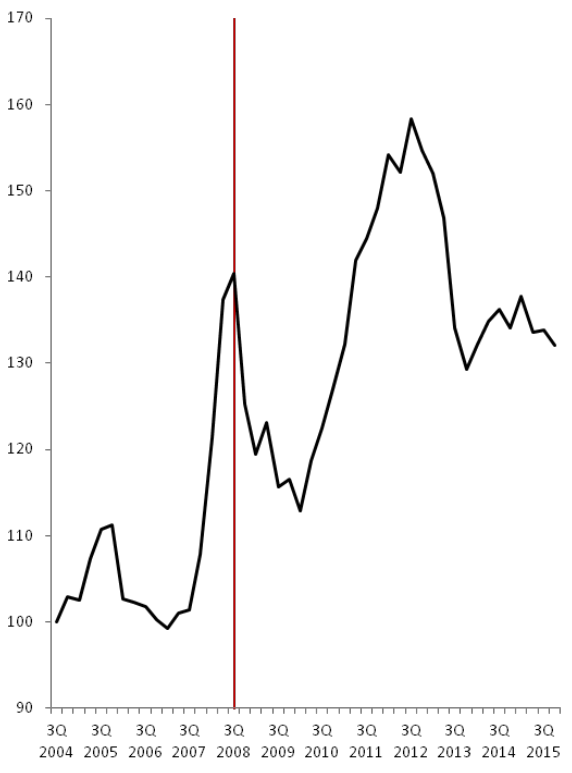

-Total debt

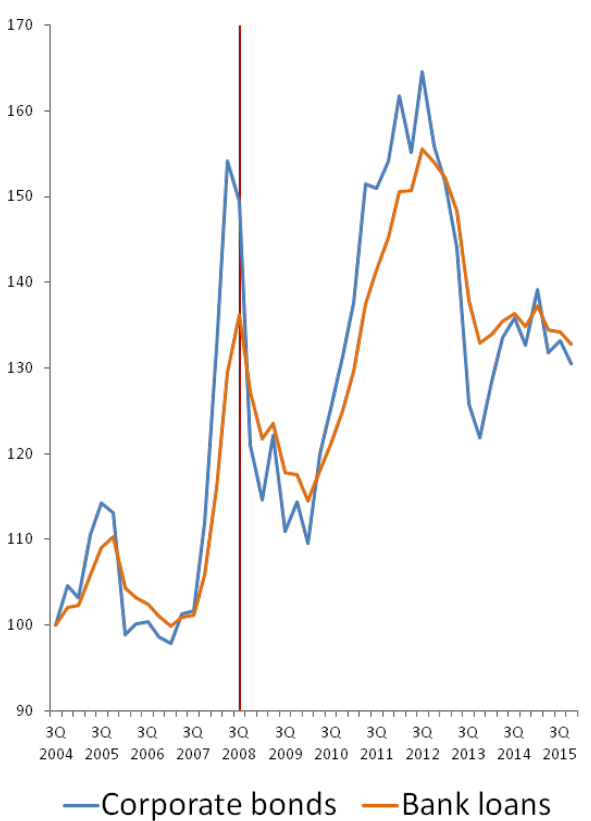

Notes: In the simulation the real interest rate shocks, proxied by fitted residuals from an $\operatorname{AR}(1)$ process on the real ex ante 10 year US bonds rate, are fed to the model. The left panel plots the total amount of corporate external debt implied by the model, whereas the right panel splits this debt into stocks of bank loans $B L_{t}$ and bonds $C B_{t}$. All simulated series are in levels and normalized to 100 for the first period of the simulation. Vertical line indicates the collapse of Lehman Brothers. Sources: Bloomberg, University of Michigan and authors' computations. 
Figure 5: Simulation of consumption and investment following $R^{*}$ shocks, 3Q $2004-4 \mathrm{Q}$ 2015.

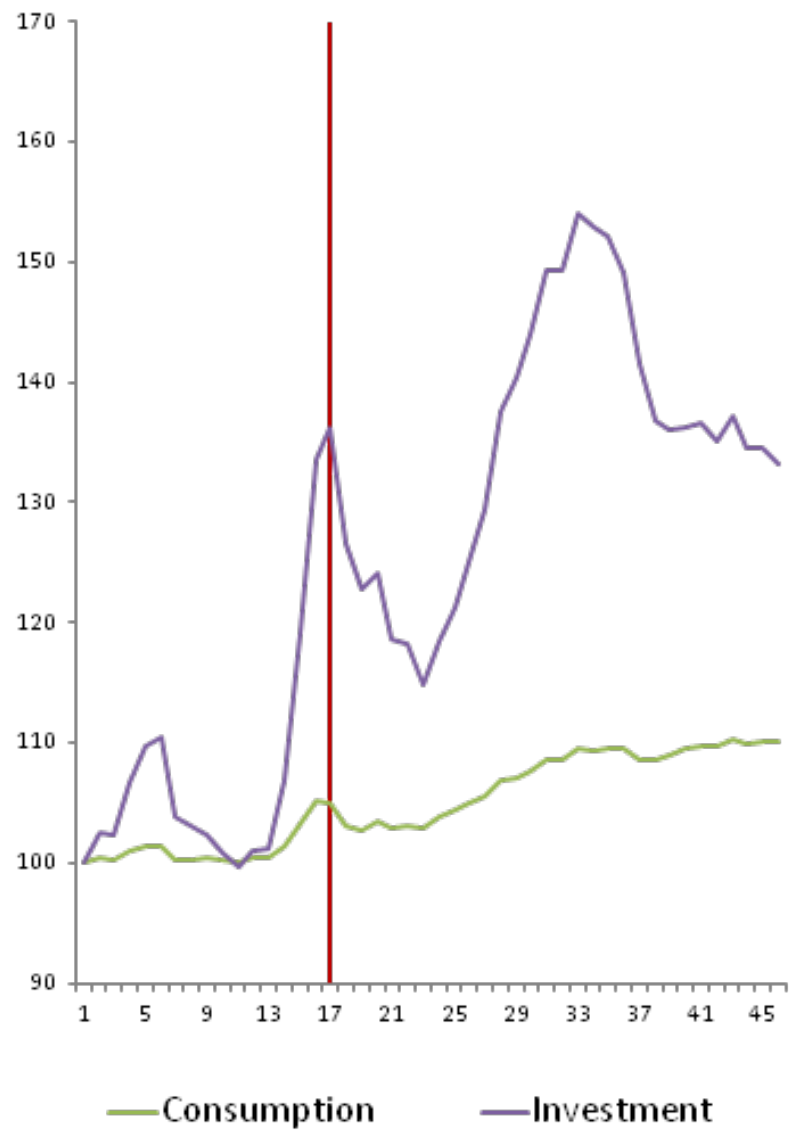

Notes: In the simulation the real interest rate shocks, proxied by fitted residuals from an AR(1) process on the real ex ante 10 year US bonds rate, are fed to the model. All simulated series are in levels and normalized to 100 for the first period of the simulation. Vertical line indicates the collapse of Lehman Brothers. Sources: Authors' computations. 
Figure 6: Counterfactual impulse responses to one percentage point drop in $R^{*}$ with high $c$.
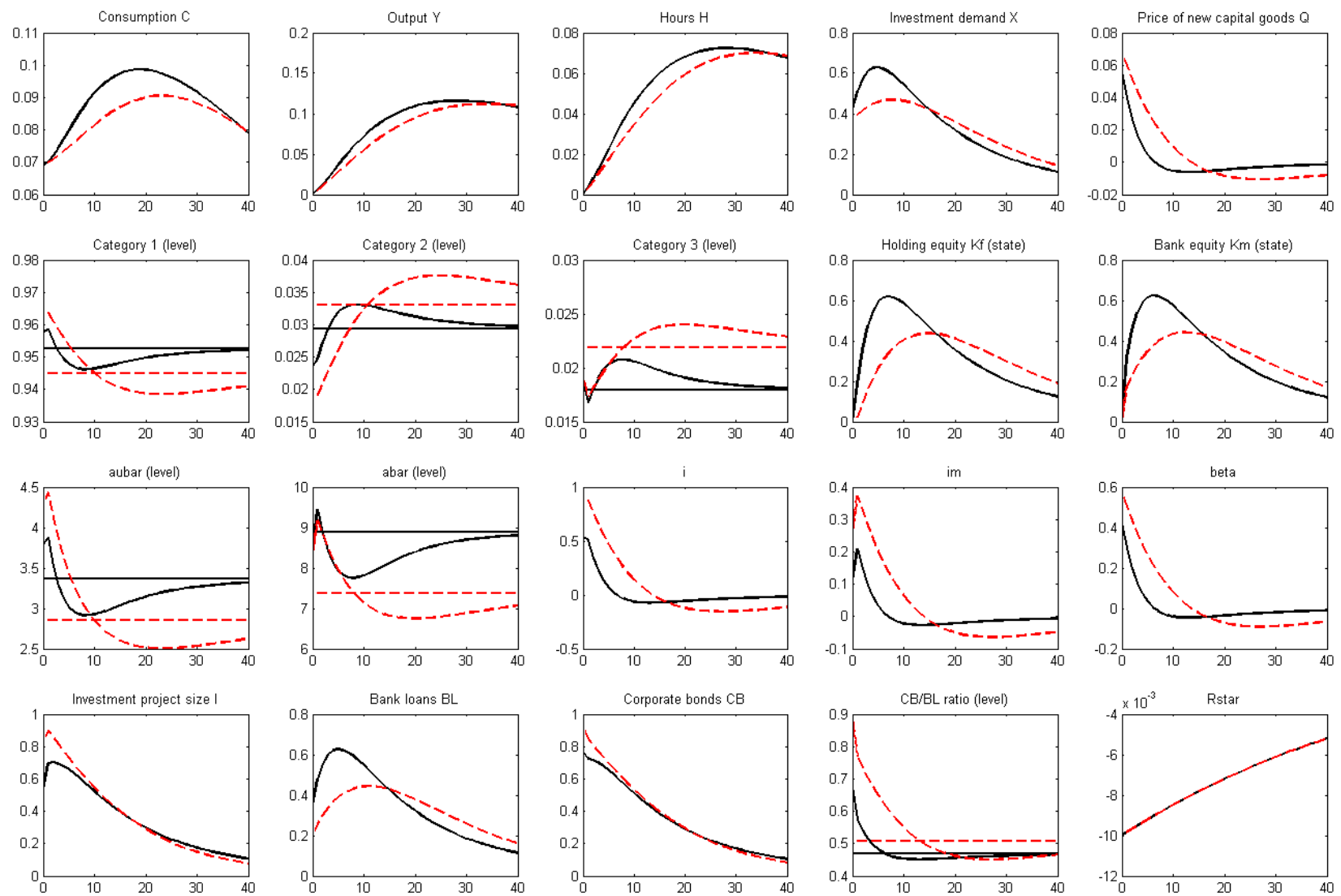

Notes: $c$ is higher by $1 / 3$ relative to the benchmark. All variables plotted are percentage deviations from the non-stochastic steady state, unless indicated that they are in levels. This applies to the IRFs for the three categories, cutoffs and the bond-to-loan ratio. Black lines denote the benchmark and red lines denote the counterfactual. Horizontal dashed lines denote steady state values of the variables plotted in levels. 
Figure 7: Counterfactual impulse responses to one percentage point drop in $R^{*}$ with low $B$.
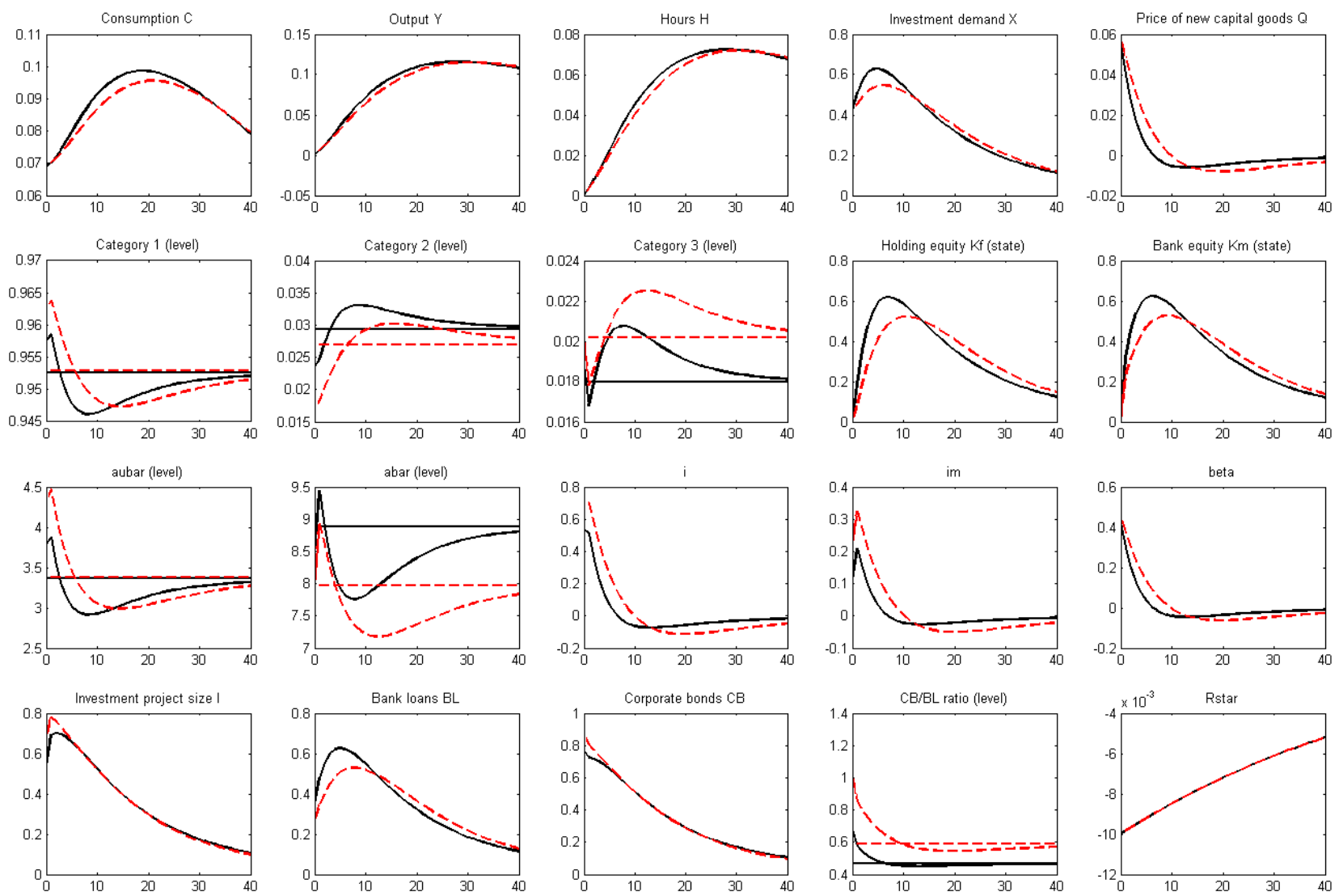

Notes: $B$ is lower by $10 \%$ relative to the benchmark. All variables plotted are percentage deviations from the non-stochastic steady state, unless indicated that they are in levels. This applies to the IRFs for the three categories, cutoffs and the bond-to-loan ratio. Black lines denote the benchmark and red lines denote the counterfactual. Horizontal dashed lines denote steady state values of the variables plotted in levels. 
Figure 8: Commodity Prices and Interest Rate Spreads in Emerging Markets.
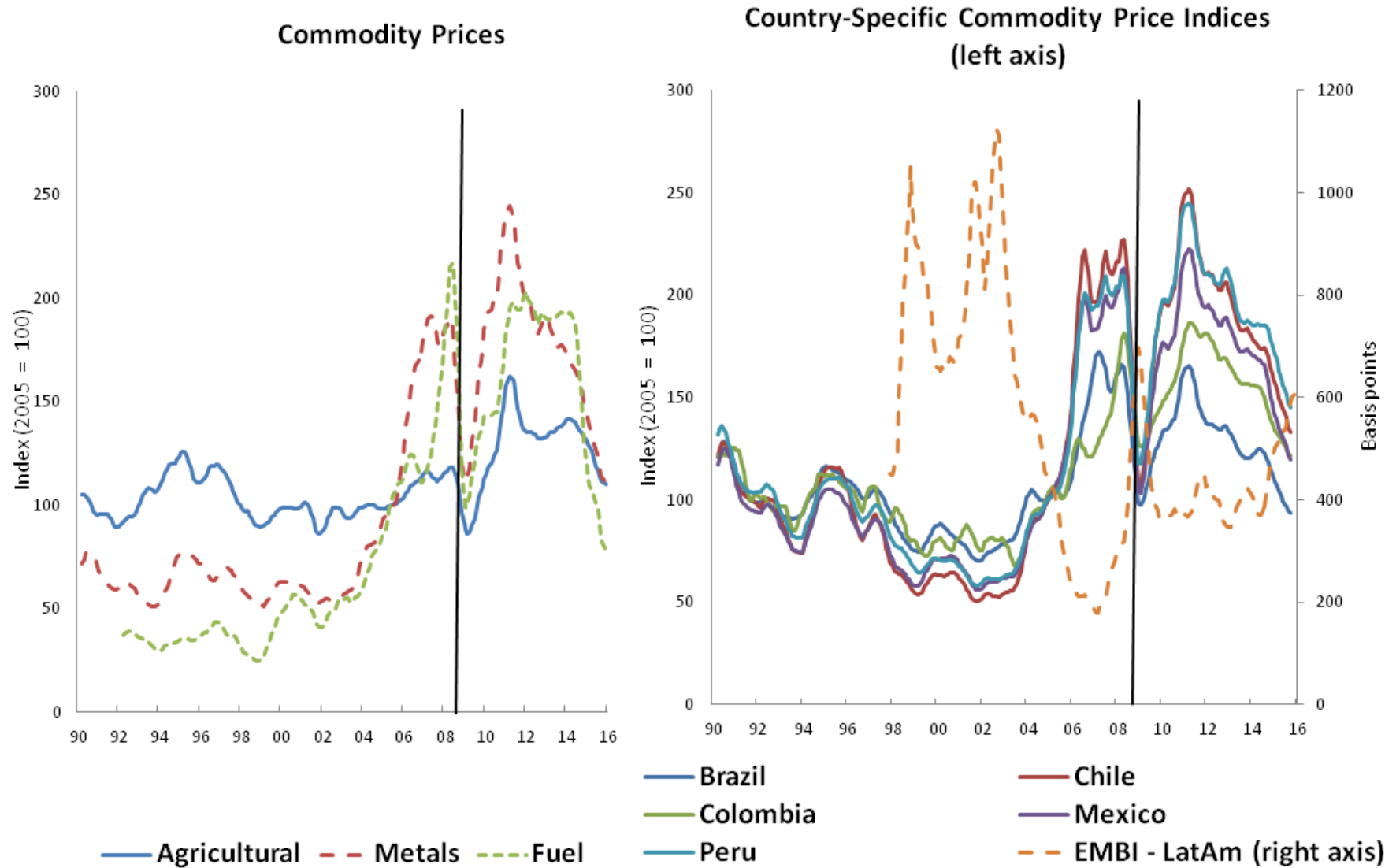

Notes: The left panel plots the price indices for each of the three broadest categories of commodity goods: raw agricultural products, metals and fuels. The right panel plots country-specific commodity price indices for Brazil, Chile, Colombia, Mexico and Peru alongside the Latin American EMBI spread. The original series are smoothed using a centered rolling moving average window of 6 months. Vertical lines indicate the collapse of Lehman Brothers. Sources: IMF, Bloomberg and Fernández et al. (2015) 
Figure 9: Impulse responses to one percentage increase in commodity price $P^{C}$.
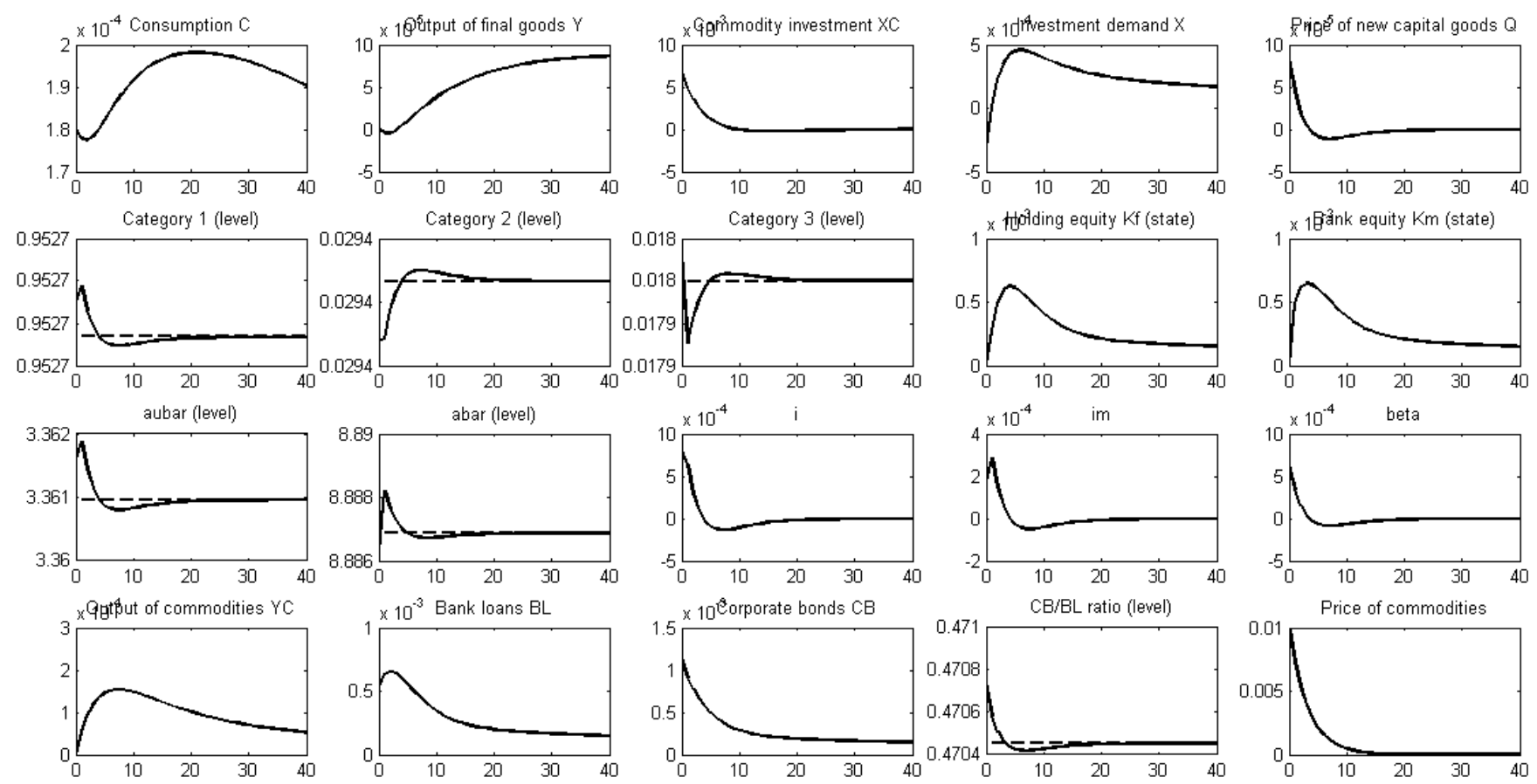

Notes: All variables plotted are percentage deviations from the non-stochastic steady state, unless indicated that they are in levels. This applies to the IRFs for the three categories, cutoffs and the bond-to-loan ratio. Horizontal dashed lines denote steady state values of the variables plotted in levels. 


\section{Table 1: Calibrated parameters.}

\begin{tabular}{cccc} 
Parameter & Description & Value & Source \\
\hline$\varphi$ & cost of capital adjustment & 4.602 & Fernández and Gulan (2015) \\
$\tilde{\Psi}$ & risk premium elasticity & 0.001 & Schmitt-Grohé and Uribe (2003) \\
$\beta$ & rate of return to bank equity & 1.0364 & Cihák et al. (2013) \\
$p_{H}$ & high probability of project success & 0.99 & Meh and Moran (2010) \\
$p_{L}$ & low probability of project success & 0.96 & min. satisfying $\beta>\frac{p_{H}}{p_{L}}$ \\
$\alpha$ & Cobb-Douglas capital share & 0.32 & Aguiar and Gopinath $(2007)$ \\
$K / Y$ & capital-to-quarterly output ratio & 8 & Kehoe and Meza (2012) \\
$\beta^{h}$ & Households' discount factor & 0.9852 & found endogenously \\
$\delta$ & Depreciation rate & 0.025 & found endogenously \\
$\mathcal{A}$ & TFP & 1 & normalization \\
$H$ & labor time & 0.33 & Aguiar and Gopinath (2007) \\
$Q$ & price of capital & 1 & normalization \\
$X / Y$ & investment to output ratio & 0.2 & Data \\
$C / Y$ & consumption-to-output ratio & 0.746 & Fernández and Gulan (2015) \\
$R^{*}$ & foreign interest rate on HH debt & $0.49 \%$ & Data (non-annualized) \\
$\tau$ & GHH labor parameter & 1.6 & Neumeyer and Perri (2005) \\
$\sigma$ & relative risk aversion & 2 & Aguiar and Gopinath (2007) \\
$\rho_{R^{*}}$ & persistence of $R^{*}$ shock & 0.9837 & Data (non-annualized) \\
$\rho_{A}$ & persistence of $A$ shock & 0.95 & Neumeyer and Perri (2005) \\
$\sigma_{R^{*}}$ & std dev. of $R^{*}$ shock & 0.001 & Data (non-annualized) \\
$\sigma_{A}$ & std dev. of $A$ shock & 0.01 & \\
& &
\end{tabular}




\section{Table 2: Matched empirical financial ratios.}

\begin{tabular}{lccc} 
Condition & Model & Target & Target Source \\
\hline Bank operating costs to bank assets & 0.0032 & 0.0078 & World Bank GFDD \\
Bank assets to bank equity & 9.7639 & 10.6444 & World Bank GFDD \\
Holding assets to holding equity & 4.7582 & 1.7100 & Fernández and Gulan $(2015)$ \\
Gross foreign bank loans stock to GDP & $11.64 \%$ & $19.28 \%$ & BIS \\
Gross foreign corporate bond stock to GDP & $5.48 \%$ & $6.28 \%$ & BIS \\
FOC of the holding & 0 & 0 & equation 14 \\
\hline Notes: For flow variables, quarterly (non-annualized) data is used. For the "FOC of the holding", 0 \\
indicates that the equation is exactly satisfied (i.e. LHS - RHS = 0).
\end{tabular}


Table 3: Calibrated financial parameter values.

\begin{tabular}{lcccccc} 
Parameter & $c$ & $b$ & $B$ & $\sigma_{G}$ & $i=\frac{I}{K^{f}}$ & $R$ \\
\hline Calibrated value & 0.0030 & 0.0011 & 0.0031 & 2.2789 & 92.3384 & 1.0149
\end{tabular}




\section{Table 4: Counterfactual steady state.}

\begin{tabular}{cccc} 
Variable & Benchmark & High $\boldsymbol{c}$ & Low $\boldsymbol{B}$ \\
\hline$i$ & 92.3384 & 77.2777 & 92.3520 \\
$I$ & 3.6931 & 3.1759 & 3.7098 \\
$Q$ & 1.0000 & 1.0007 & 0.9998 \\
$X$ & 0.1756 & 0.1753 & 0.1757 \\
$K$ & 7.0240 & 7.0128 & 7.0266 \\
$r^{K}$ & $4.000 \%$ & $4.0028 \%$ & $3.9994 \%$ \\
$Y$ & 0.8780 & 0.8772 & 0.8782 \\
$C$ & 0.6550 & 0.6544 & 0.6645 \\
$K^{f}$ & 0.0400 & 0.0411 & 0.0402 \\
$K^{m}$ & 0.0105 & 0.0135 & 0.0097 \\
$\bar{a}$ & 8.8869 & 7.3821 & 7.9702 \\
$\underline{a}$ & 3.3610 & 2.8481 & 3.3763 \\
Category 2 & 0.0294 & 0.0331 & 0.0270 \\
Category 3 & 0.0179 & 0.0219 & 0.0202 \\
$C B$ & 0.0481 & 0.0501 & 0.0558 \\
$B L$ & 0.1022 & 0.0989 & 0.0945 \\
\hline
\end{tabular}

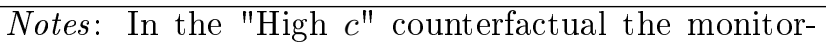
ing cost parameter $c$ is increased by $1 / 3$ relative to the benchmark. In the "Low $B$ " counterfactual the private benefit parameter $B$ is reduced by $10 \%$ relative to the benchmark. In both counterfactuals all other parameters are kept unchanged and endogenous variables are allowed to adjust. 